\title{
Long-lasting impact of starvation experience on fly activity and place preference
}

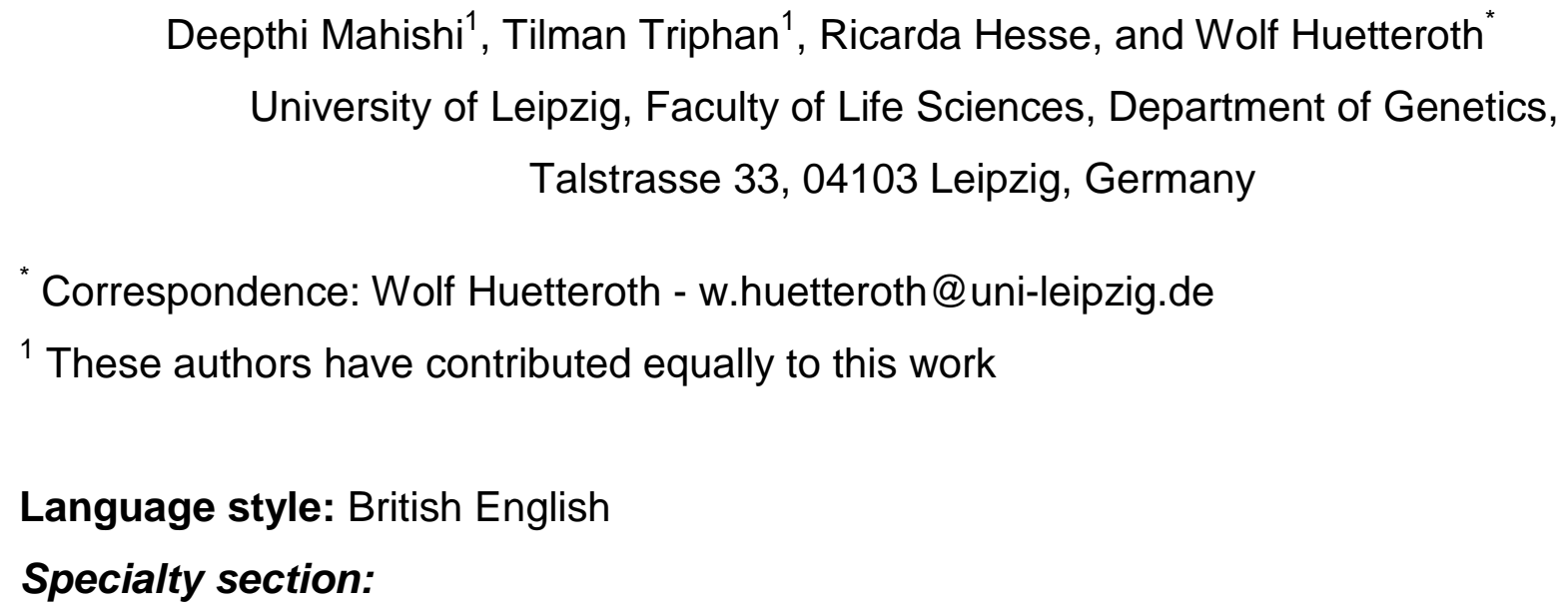

This article was submitted to Individual and Social Behaviors, a section of the journal Frontiers in Behavioral Neuroscience

Keywords: Drosophila, feeding, foraging, place preference, tracking

\section{Abstract}

Animal behaviours are demonstrably governed by sensory stimulation, previous experience and internal states like hunger. With increasing hunger, priorities shift towards foraging and feeding. During foraging, flies are known to employ efficient path integration strategies. However, general long-term activity patterns for both hungry and satiated flies in conditions of foraging remain to be better understood. Similarly, little is known about how chronic contact chemosensory stimulation affects locomotion. To address these questions, we have developed a novel, simplistic fly activity tracking setup - the Panopticon. Using a 3D-printed Petri dish inset, our assay allows recording of walking behaviour, of several flies in parallel, with all arena surfaces covered by a uniform substrate layer. We tested two constellations of providing food: i) in single patches, and ii) omnipresent within the substrate layer. Fly tracking is done with FIJI, further assessment, analysis and presentation is done with a custom-built MATLAB analysis framework. We find that starvation history leads to a long-lasting reduction in locomotion, as well as a delayed place preference for food patches not driven by immediate hunger motivation. 


\section{Introduction}

Flies show hunger-motivated ranging or foraging walks to find food; they also show explorative walks (or local searching behaviour) after food encounter (Dethier, 1957; Bell et al., 1985; Bell, 1990; Corrales-Carvajal et al., 2016; Kim and Dickinson, 2017; Murata et al., 2017; Hughson et al., 2018; Mahishi and Huetteroth, 2019), and much has been achieved in identifying the circuits and dynamics involved in this behaviour (Corfas et al., 2019; Lin et al., 2019; Moreira et al., 2019; Sayin et al., 2019; Seidenbecher et al., 2020). Most of these studies either used hunger-motivated behaviour to focus on the underlying navigational strategy of the flies, or they focused on exploration-exploitation trade-offs under different motivational settings.

Interestingly, both hedonic and caloric value of the food source can influence explorative walks. The perceived sweetness after ingestion correlates to the duration and path length of explorative walking (Murata et al., 2017), and protein-sated flies venture further away from a yeast patch than protein-deprived flies (Corrales-Carvajal et al., 2016). As satiation levels drop with ongoing post-prandial energy expenditure, finding food is becoming increasingly important. An exploring fly constantly assesses palatability with its tarsal chemosensors, supported by occasional proboscis extension (Mahishi and Huetteroth, 2019). But how much does a fly explore when nutritional homeostasis can be achieved anywhere?

What are the locomotion dynamics independent of food search? To overcome distorting foraging locomotion, driven by constantly changing hunger levels, we provide an arena with omnipresent food. Although these previous studies imply foraging-independent explorative walking in sated flies (Bell et al., 1985; Bell, 1990; Murata et al., 2017), no study exists to our knowledge that studied prolonged intrinsic walking behaviour on a homogenous food substrate, where any locomotion motivated by food-seeking can be ruled out.

It is also not well understood how palatability and satiation affect walking activity beyond the first 3-120 min after food interaction; food-related responses can exert their physiological and behavioural effects on longer timescales. Larval diet composition impacts adult food choice (Davies et al., 2018), and preference of a caloric diet over an equally palatable alternative is only established after several hours (Dus et al., 2011; 
Stafford et al., 2012). Similarly, a dietary imbalance between palatability and nutritional content is leading to sustained physiological changes much later (Wang et al., 2016, 2017; Musso et al., 2017; Park et al., 2017; May et al., 2019). Apart from few exceptions (Martin, 2004; Meunier et al., 2007), most existing fly locomotion studies either examine short periods at high temporal resolution (Kim and Dickinson, 2017; Murata et al., 2017; Brockmann et al., 2018; Hughson et al., 2018; Landayan et al., 2018), or sample for short recurring time windows to cover longer periods (Green, 1964a, 1964b; Connolly, 1966a; Barwell et al., 2020). Automated circadian studies provide both temporal resolution and timespan, but focus on changes in rhythmicity (Guo et al., 2016; Pegoraro et al., 2020), and rarely include location preferences or locomotion in a nutritional context (Donelson et al., 2012; Dreyer et al., 2019).

We use uninterrupted video tracking $(1 \mathrm{~Hz})$ of starved and fed flies to compare locomotion activity and location probability for over $24 \mathrm{~h}$ in two conditions: i) a foraging setting with a single food patch, or ii) with homogenous food substrate on all surfaces. Our assay comes with a data pipeline from recording to analysis utilizing custom-written camera recording software, FIJI-based tracking, and MATLAB-based data analysis, various sanity check functions and visualization.

\section{Material \& Methods}

Animals

All experiments were performed with 2-5 day old male Oregon $^{\mathrm{R}}$ flies, maintained the University of Leipzig at $25{ }^{\circ} \mathrm{C}$ and $60 \%$ humidity on a 14:10 LD cycle on standard fly food. Starved animals were kept for $22-24 \mathrm{~h}$ in empty vials with added wet tissue, fed flies were allowed to feed ad libitum on normal fly food until testing.

\section{Panopticon assay}

Cold anesthetised fed and starved male flies were alternately placed in individual sectors of the Panopticon and then transferred onto the imaging rig (Fig. 1A), which is located inside a climate chamber (not shown) to maintain constant levels of $60 \%$ humidity and a temperature of $25^{\circ} \mathrm{C}$. The Panopticon consists of a 3D-printed arena (.stl file; Renkforce RF1000: Material PLA white), which is inserted in the lid of a standard plastic Petri dish (85 mm, Greiner) partially filled with substrate $(1 \%$ agarose 
or $1 \%$ agarose containing $200 \mathrm{mM}$ sucrose), separating it in eight sectors (5.5 $\mathrm{cm}^{2}$ each) (Fig. 1B). During insertion of the plastic arena into still viscous substrate we assured homogenous coating of all inner walls before solidification. For foraging experiments, small Eppendorf lids were used to create individual food containers in each arena (food patches, $0.2 \mathrm{~cm}^{2}$ ). The $1 \%$ agarose with $200 \mathrm{mM}$ sucrose in these food patches was levelled with the surrounding $1 \%$ agarose to avoid confounding effects of negative geotaxis on place preference (Robie et al., 2010). The Panopticon was closed with another inverted Petri dish lid with a layer of substrate to provide equal surface texture on all sides (Fig. 1B). Data collection was started as soon as all flies regained walking ability (within 1 min of transfer). Images (1024 X 1024 px) were recorded with a camera (Basler acA1300-200uc) at 1 frame per second for $24 \mathrm{~h}$.

\section{Tracking and analysis}

The recorded images were processed in batches using a custom-written, FIJI-based macro. Object information was extracted and saved as csv files. Results were then further handled using a data analysis script written in MATLAB 2018a, which provides various sanity check functions and visualization. Some plots make use of the "shadedErrorBar" function (Campbell, 2020). Activity and place preference plots are either aligned according to start time ( $1 \mathrm{~h}$ plots) or time of day ( $24 \mathrm{~h}$ plots). To exclude movements caused by camera noise we set a minimum threshold of 2 pixels $(0.1 \mathrm{~mm})$ and treated the fly as stationary in this case. Regions of interest for place preference (food patches, same-sized virtual food patches) were created in MATLAB. For further details on analysis and plotting functions see Results and Code, and the Readme file available on Github (https://github.com/dmahishi/Panopticon.git). Fast and efficient data handling allows for tracking and analyses of $24 \mathrm{~h}$ data (recorded at $1 \mathrm{~Hz}$ ) in about $4 \mathrm{~h}$ on a regular desktop PC (Ryzen 3 3200G, 16 GB RAM, Intel SSD 660p 512GB).

\section{flyPAD}

Food sip measurements were performed on the flyPAD (Itskov et al., 2014). Animals were fed or starved as before, anesthetized on ice and then transferred into individual flyPAD chambers with added wet tissue to allow for $24 \mathrm{~h}$ recordings. Data analysis took place with a customized version of the MATLAB script for the flyPAD (Itskov et al., 2014).

\section{Statistics}


126

127

128

129

130

131

132

133

134

135

136

137

138

139

140

141

142

143

144

145

146

147

148

149

150

151

152

153

154

155

156

157

All statistical analyses were conducted using GraphPad Prism $8 \circledR$. Multiple pairwise comparisons (paired t-tests) in case of activity and place preference plots and two-way ANOVA tests for displacement distribution and stop duration plots with Bonferroni-Dunn correction were performed.

\section{Results}

Paradigm and data pipeline for image based tracking of fly locomotion

We designed a novel, low-cost fly activity tracking setup, the Panopticon (Fig. 1). Walking behaviour of eight flies can be recorded simultaneously for up to $24 \mathrm{~h}$. All arena walls and the top lid are covered in $1 \%$ agarose (with or without $200 \mathrm{mM}$ sucrose) to both provide equal surface texture on all sides and to maintain humidity levels and avoid desiccation, allowing continuous recordings for up to a week (data not shown). Experiments were performed in constant darkness (DD) with IR lighting (850 nm) to provide constant environmental conditions. It has been previously shown that DD is less disruptive to fly activity pattern than constant light (LL) (Green, 1964a).

We devised a complete data pipeline from recording to analysis (Fig. 2). Image recording utilizes custom-written camera recording software. Subsequently, the recorded images are analysed in batches using a custom-written, FIJI-based macro script. After background subtraction and pre-processing of the images objects are extracted and saved. The results are further analysed in a custom, MATLAB-based data analysis framework. Here, basic quality control and error checking functions are applied. At first, we calculated the rate of missed/failed detections, and experiments with an error rate of more than 5\% were excluded from further analysis (Suppl. Fig. S1A). In the second step, we did a visual inspection of the walking traces (shown with a temporal colour code) to check for obvious detection errors (Suppl. Fig. S1B,C). As the last step we did a sector-wise plotting of particularly long frame-to-frame movement events that could be associated with potentially false-positive detections (Suppl. Fig. S1D). After this initial quality control, derived parameters like activity patterns and location probabilities are calculated.

\section{Starved flies appear sated within 30 min of food provision}

First we assessed how hunger impacts locomotion activity during food search, and within which timescale the effect subsides after provision of food. Finding a food patch 
158 is well studied, and we know from existing data that locomotion increases with starvation level (Connolly, 1966b; Knoppien et al., 2000) and changes its dynamics after food patch encounter (Dethier, 1976; Corrales-Carvajal et al., 2016; Kim and Dickinson, 2017; Murata et al., 2017). Using the Panopticon with food patches, we find that both starved and fed flies exhibit increased activity for about 20-30 min in their new environment, as reported before (Soibam et al., 2012). This initial increased activity is significantly more pronounced in starved flies during the first $30 \mathrm{~min}$ (Fig. 3A), which correlates with compensatory overeating as soon as food is available (Carvalho et al., 2005). Flies need to stop to feed, and there is a reciprocal relation between the two behaviours (Mann et al., 2013). Accordingly, there is a significantly higher number of short duration stops (2-7 s) on the food patch during the first 30 min (Fig. 3B), which soon shift during the subsequent 30 min towards less frequent, longer breaks (Fig. 3C). At this point, both starved and fed flies reach equally low levels of activity (Fig. 3A). This pattern is reflected in sip numbers, as independently determined on the flyPAD, which provides a good estimate of actual food intake (Itskov et al., 2014). Starved flies exhibit a significantly higher sip number as fed flies during the first 20-30 min (Fig. 3D). After 30 min, sip numbers reach equal baseline levels (Fig. 3E), suggesting comparable satiation in both initially starved and fed flies. This is in accordance with previous studies that demonstrated reduced activity after a meal (Murphy et al., 2016).

Taken together, our data shows that during the first $30 \mathrm{~min}$ starved flies exhibit increased activity, and an increased number of stops lasting between 2-7 s. These most likely reflect feeding bouts, which soon disappear when they presumably reach hunger motivation levels comparable to fed flies during the following $30 \mathrm{~min}$.

Starvation state affects $24 \mathrm{~h}$ walking activity and place preference in a food patch assay Interestingly, despite the quick compensation in feeding motivation, we observe behavioural differences in locomotion between experimental groups in the long term. Fed flies exhibit a characteristic evening activity peak before the subjective night, which is missing in starved flies (Fig. 4A). This elevated evening activity in fed flies is accompanied by a significantly higher number of short-stop events in a representative 30 min time window (Fig. 4B). On the morning of the next subjective day, stop rates decreased to comparably low levels in both experimental groups (Fig. 4C). To see if this bias during the subjective evening is reflected in speed characteristics, we looked at displacement between frames as a proxy for velocity. However, displacement up to 2 
$191 \mathrm{~mm} / \mathrm{s}$ on the food patch in the same time window (19:00-19:30) is not significantly 192 different between fed flies and starved flies (Fig. 4D). On the subjective next morning 193 (08:30-09:00), movement has slowed down equally in both groups (Fig. 4E). Whereas 194 locomotive differences between initially starved and fed flies disappear on the subjective morning next day, another effect in positional preference becomes more pronounced; initially starved flies increasingly prefer to sit on or close to the food patch (Fig. 4F).

To summarize, we see that satiation state impacts locomotion and place preference across the day. Within the first hour, starved flies are more active than fed flies, and supposedly compensate their caloric deficit in bouts of short stops until they reach food intake homeostasis. Afterwards, pre-starved flies show reduced activity, particularly during the subjective evening as compared to their fed control group. Interestingly - and despite equivalent hunger motivation - initially starved flies develop increased preference for the food patch over $24 \mathrm{~h}$.

Initially starved flies are equally active as fed flies for the majority of the observed $24 \mathrm{~h}$ timespan (Fig. 4A), yet they increasingly confine themselves to the spatially restricted food patch (Fig. 4F). How does this impact the flies' velocity? As an approximation, we examined the displacement distribution across $24 \mathrm{~h}$ between both experimental groups, and found that short displacements of up to $2 \mathrm{~mm}$ in the arena were significantly more common in starved flies than in fed flies (Fig. 5A). These short movements are mostly found to be associated with the food patch (movements on patch itself, as well as movements onto patch or off the patch) (Fig. 5B), whereas short movements outside the

213 patch occur with equally low frequency in both experimental groups (Fig. 5C). This

214 suggests that both starved and fed flies have comparable internal drives to move, and 215 the location bias of starved flies towards the food patch is compensated by a 216 significantly higher number of short distance moves of up to $2 \mathrm{~mm}$. behave when we take away the need for foraging altogether, when hunger can be satiated anytime, anywhere? In such a context, we adjusted the assay by removing the

221 food patches and instead lacing all inner surfaces with a homogenous layer of $1 \%$ 
223 (Fig. 3A) was reduced by about $15 \%$ on omnipresent food in fed flies (Fig. 6A); with 224 about $50 \%$ this effect was even more pronounced in starved flies. The stop lengths in 225 the food-covered arena during the first $30 \mathrm{~min}$ are comparable between both 226 experimental groups (Fig. 6B), but there is a robust dichotomy in average speed 227 distribution: starved flies preferably move at average speeds up to $2 \mathrm{~mm} / \mathrm{s}$, wherein fed 228 flies travel substantial and significant distances at average speeds between 5-10 mm/s 229 during this time window (Fig. 6C).

230 During the subsequent $30 \mathrm{~min}$, when initially starved flies supposedly adjusted their 231 caloric needs, stop lengths remain similar (Fig. 6D). But while starved flies still 232 significantly prefer slow movements, the preference becomes less pronounced and the 233 shift towards higher average velocities reaches comparable levels between 5-10 mm/s 234 in both groups (Fig. 6E). The initially lower activity of pre-starved flies as compared to 235 that of fed flies disappears during the remainder of the $24 \mathrm{~h}$ experiment duration. In fact, 236 this even includes a reinstated evening activity peak in pre-starved flies (Fig. 6F). A 237 virtual food patch (i.e. an area of equivalent size to the food patch) in the omnipresent 238 food arena shows no place preferences for both groups (Fig. 6G). It has been reported 239 that flies kept on sugar increase their locomotion in contrast to flies kept on agarose 240 (Lim et al., 2014). Indeed it appears as if overall levels of activity in the omnipresent 241 sucrose arena are slightly elevated, in comparison with fly activity levels in the food 242 patch arena (Fig. 4A, 6F). Taken together, ubiquitous food presentation dampens initial 243 hyperactivity during the first $30 \mathrm{~min}$, and restores the activity peak during subjective 244 evening in starved flies.

As mentioned before, homogenous food distribution in the Panopticon results in equivalent stop dynamics for both starved and fed flies. Indeed, this holds true across all examined time windows (Fig. 6B, D, H, J), and is different to what we observed on food patches before (Fig. 3B,C; Fig. 4B,C). Similar to before however, initially starved flies retain a significant prevalence for slower average speeds up to $2 \mathrm{~mm} / \mathrm{s}$ (Fig. $6 \mathrm{C}, \mathrm{E}, \mathrm{I}, \mathrm{K}$ ), just as seen in the food patch arena (Fig. 5). This reduced average velocity persists even during later time points when both experimental groups likely have comparable satiety levels - and no carbohydrate restrictions whatsoever. Due to its 
255 feature of the flies' nutritional history. Taken together, this implies a long-lasting effect of starvation experience on average velocity independent of localised food patches.

\section{Discussion}

The Panopticon represents a cost-effective, Petri dish-based locomotion assay which we utilise in two configurations: i) a classical foraging assay with a single food patch, and ii) an omnipresent food configuration, where every surface in the arena is uniformly covered by substrate. In such a scenario, non-foraging explorative walking behaviour is dissociated from foraging-related search and exploration walking; the flies' chemosensors are chronically stimulated and every arena location is equally suited to provide food. Due to constant food provision and humidity buffering, longer-lasting recordings (up and beyond $24 \mathrm{~h}$ ) are possible. One caveat of our experiments is that the flies are exclusively resupplied with a carbohydrate food source. Although the flies' intake target is heavily skewed towards carbohydrates (Lee et al., 2008; Tatar et al., 2014) and flies can survive on sucrose alone for weeks (Hassett, 1948), we cannot rule out additional effects by ongoing protein deprivation or possible micronutrient shortage. Nonetheless, we only tested male flies which exhibit a more pronounced skew towards sugars than females (Ribeiro and Dickson, 2010). Also, female mating status, egg

273 production and oviposition can affect consumption, as well as food and place choice

274 (Joseph et al., 2009; Carvalho-Santos et al., 2020; Hadjieconomou et al., 2020).

We do not see a pronounced morning activity peak in our assay, as would be expected from circadian studies. However, our experiments are performed in permanent dark, which ensures homogenous illumination and is less disruptive for internal rhythms than constant light (Green, 1964a). But a DD paradigm lacks a distinct visual and thermal Zeitgeber signal for morning onset, which has been shown to be the major influence on the morning activity peak, with little contribution from internal clock genes (Green et al., 2015). Furthermore, individuals within a fly population can exhibit crepuscular, diurnal and nocturnal activity pattern (Pegoraro et al., 2020); the tested flies might be skewed in their allele distribution for such circadian traits. The activity peak during the subjective evening however is very robust. Remarkably, this activity peak is only missing in one condition: in pre-starved flies on the food patch Panopticon. Starved flies do ingest 286 increased amounts of food immediately after food is resupplied (Fig. 3D). Under 
288

289

290

291

292

293

294

295

296

297

298

299

300

301

302

303

304

305

306

307

308

309

310

311

312

313

314

315

316

317

318

319

320

rather maintain an almost empty crop (Edgecomb et al., 1994). A full crop cannot only terminate feeding (Gelperin, 1971; Min et al., 2020; Wang et al., 2020a), but also limit post-prandial explorations (Murata et al., 2017). However, it is doubtful that this 'restand-digest' effect would last very long after the initial voracious re-feeding period. While fed flies always exhibit the evening activity peak, starved flies - which would be expected to have a 'rest-and-digest' period after re-feeding - have a reconstituted evening activity peak under omnipresent food conditions (Fig. 6F). This rather indicates a crucial interplay between spatial availability of nutrients and general locomotion motivation across the day to explain the activity differences during the evening in prestarved flies.

Along with the food patch location preference (Fig. 4F), the following picture emerges: it appears that the motivation for pre-starved flies to sit on the food patch could be not to stray too far from a feeding resource, which outcompetes the motivation for raised activity during the subjective evening. As soon as food is omnipresent, the location preference is gone, and evening activity is reinstated. If the place preference in previously starved flies is also triggered by gustatory activation like local food search (Murata et al., 2017) remains to be shown, for example by providing sweet-only food patches (i.e. arabinose) to rule out caloric involvement. It also remains to be shown if ongoing protein deprivation is involved; however, male flies only seek a protein source after days of prolonged protein starvation (Ribeiro and Dickson, 2010).

The second outcome is less obvious, but robust: independent of food patch presence or omnipresent food, the fed flies move faster than pre-starved flies during the course of the experiments (Fig. 5, Fig. 6C,E,I,K). This could be a delayed effect of the experienced starvation stress; prolonged vibrational stress can lead to reduced voluntary locomotion (Ries et al., 2017). Another possibility could be a long-lasting or even chronic effect on sensory perception (May et al., 2019; Vaziri et al., 2020).

Hunger is known to sensitise certain chemosensory and other circuits at the expense of others, but such sensitisation is usually reversed as soon as the caloric demand is met (Root et al., 2011; Nishimura et al., 2012; Farhan et al., 2013; Inagaki et al., 2014; Longden et al., 2014; Sachse and Beshel, 2016; Grunwald Kadow, 2019; Lin et al., 2019; Wang and Wang, 2019). Habituation and sensitisation of tarsal sugar responses are only described in the minute range (Duerr and Quinn, 1982; Scheiner, 2004; Paranjpe et al., 2012), whereas adaptation of taste-sensing neurons can occur over 
321 longer time frames, after chronic dietary intervention (May et al., 2019; Wang et al., 322 2020b). Exposure to high concentration sucrose might either differentially desensitise 323 gustatory sensilla in fed and pre-starved flies, or the prolonged hunger experience in 324 pre-starved flies leads to a chronic sensitisation of gustatory sensilla. In either case, the 325 threshold to sample the substrate would differ between the two experimental groups, 326 resulting in the observed speed differences in the Panopticon.

327 The most striking phenotype however is the increasing bias of pre-starved flies towards 328 the food patch (Fig. 4F). A similar difference in food patch interaction (although not on 329 that timescale) has been observed for sitter and Rover alleles of the foraging gene; while Rover flies show normal local search behaviour after ingestion, sitter flies tend to stay close to the food source (Pereira and Sokolowski, 1993). Flies are aware of the 332 food patch position within the arena. This is different from learning the spatial arrangement pattern of food patches, which houseflies seem to be not capable of (Fromm and Bell, 1987). But flies can remember locations and learn to efficiently navigate towards previously encountered targets like visual landmarks (Neuser et al., 2008), safe spots (Ofstad et al., 2011), or food sources (Navawongse et al., 2016), even in the dark and without usage of visual or olfactory sense (Kim and Dickinson, 2017).

338 It appears that the biogenic amine serotonin (5-HT) is involved in such place learning (Sitaraman et al., 2008, 2017; Sitaraman and LaFerriere, 2020). Furthermore, different 5-HT subsets or 5-HT regulation interfere with feeding (Albin et al., 2015; Liu et al., 2015), food seeking behaviour (He et al., 2020), locomotion (Yellman et al., 1997; Howard et al., 2019), sleep architecture (Liu et al., 2019), and quiescence (Pooryasin and Fiala, 2015). Thus, 5-HT manipulation provides a good candidate for further studies in the Panopticon (Tierney, 2020). Similarly, octopamine (OA) and tyramine (TA) influence locomotion in a state-dependent manner; starvation shifts the OA/TA balance via TBH expression levels and leads to 347 hunger-induced hyperactivity (Yang et al., 2015; Schützler et al., 2019). A single OA neuron signals satiation and stops food-motivated search (Sayin et al., 2019), and the same neuron can initiate feeding behaviour (Youn et al., 2018). Also, OA influences

350 AKH signalling for diurnal pattern generation (Pauls et al., 2020), and might be affected 351 in starved flies during the blocked evening activity peak. Given the pleiotropic actions of 352 OA, place preference may be impacted as well (Selcho and Pauls, 2019). 
353 The food patch location is most likely associated with food reward in both fed and 354 starved flies, analogous to odour associations with caloric value (Burke and Waddell, 355 2011; Fujita and Tanimura, 2011; Huetteroth et al., 2015; Ichinose et al., 2015; Musso 356 et al., 2015; Yamagata et al., 2015; Zhang et al., 2015). Such long-lasting, food-related 357 odour memories are stored in the mushroom body (MB) (Krashes and Waddell, 2008), 358 and it is clear that this structure, especially its zonal dopaminergic modulatory 359 innervation, has a central instructional role in motivational foraging and feeding (Tsao et al., 2018; Musso et al., 2019; May et al., 2020).

361 In the Panopticon experiment, the food-place association could be enforced by two 362 factors in starved flies: First, the absolute amount of food that is ingested by starved 363 flies within the first $30 \mathrm{~min}$ is bigger, since they supposedly need to cover their caloric 364 deficit (Fig. 3D). Secondly, the lack of caloric signals during starvation renders food365 associative MB circuits particularly sensitive to the next food encounter (Hirano and Saitoe, 2013; Hirano et al., 2013, 2016; Plaçais et al., 2017; Wu et al., 2018). For example, starved flies, contrary to fed flies, do not require additional sleep to consolidate a food-odour association (Chouhan et al., 2020). It appears the subjectively perceived value of food is higher in starved flies than in fed flies. So during this time of transition in a new environment, both quantity and perceived quality of the ingested food on the food patch would be higher for starved flies. These two effects together could lead to a strong and long-lasting positive association with the food patch location that influences location decision making beyond nutritional demand for the subsequent $24 \mathrm{~h}$.

However, some issues are not addressed by this explanation. Retrieval of a foodassociated memory depends on the motivational incentive of hunger; a starved fly will utilize an olfactory food association to increase its chances to feed, whereas fed flies will only do so after being starved once more (Krashes and Waddell, 2008). Similarly, starved flies would have a higher incentive to retrieve and use their place memory of the food patch location, and indeed, starved flies exhibit a higher and more frequent return rate to a known food patch, be it real or virtual (Corrales-Carvajal et al., 2016; Kim and Dickinson, 2017; Murata et al., 2017; Corfas et al., 2019; Haberkern et al., 2019). depends on concurrent hunger as the motivational drive to retrieve spatial memory. All other food-related behaviours like activity, stop distribution or sip number are aligned 
386 from then onwards (Fig. 3), and protein hunger only starts to influence male food choice 387 much later (Ribeiro and Dickson, 2010). It also needs to be taken into account that food 388 association in the Panopticon is not formed with odours but with place, and associations 389 of spatial features involve the central complex (Liu et al., 2006; Stern et al., 2019); it is equally possible that plastic changes in this structure contribute to the observed location preference. In a place learning assay, the unavoidability of an aversive heat stimulus can boost its reinforcing propensities (Sitaraman and Zars, 2010); it is feasible that the same is the case for unavoidable starvation.

394 How could this work? This reminds of long-lasting, non-associative and associative learning effects, mostly known from the classic Aplysia gill- and siphon-withdrawal reflex (Pinsker et al., 1973; Cassel, 2010; Cai et al., 2011). Repeated noxious stimuli on the tail or neck of this sea slug sensitise the animal so that subsequent normal mechanosensory stimulation of the siphon results in exaggeratedly strong gill and siphon withdrawal (Frost et al., 1985). The same pathways were shown to be also involved in classical conditioning experiments of the gill- and siphon-withdrawal reflex 401 (Hawkins et al., 1983). In our case, the sensitising noxious signal is replaced by an internal need (hunger), whereas the sensitised motor response is replaced by a decision-making circuit (bias to stay on food).

But why does this effect appear to become stronger over time? It might be possible that the starved flies generalise from the starvation experience, and hence seek proximity to the food source. Increasing generalisation of an aversive stimulus over time is not only observed for odour-shock learning in flies (König et al., 2017), but is also a characteristic feature of post-traumatic stress disorders in both animals and humans (Stam, 2007). A similar long-lasting effect has been described for predator-induced oviposition preference (Kacsoh et al., 2015). Here, gravid female flies are exposed to parasitoid wasps for several hours. After removing the wasps, the females choose 412 ethanol-laced patches over control patches for days (fly larvae have a higher ethanol 413 tolerance than wasp larvae). As in the Panopticon, prolonged exposure to a distressing 414 stimulus (hunger or parasitoid wasps) influences a later choice (place preference) even 415 after the stressor was removed. Interestingly, MB inhibition and several memory 416 mutants abolished this long-lasting skew exclusively after wasp removal, but not under 417 immediate threat; it will be interesting to see how MB function and memory genes 418 impact the place preference on the Panopticon. 


\section{Outlook}

421 We present here a new paradigm to examine locomotion behavior and place 422 preference, under foraging conditions (food patch Panopticon) or under chronic 423 chemosensory stimulation (omnipresent food Panopticon). The food patch Panopticon 424 will help to examine the neuronal circuits underlying long-lasting effects of starvation on 425 place preference, and how this apparently non-associative process relates to known 426 associative long-lasting memory function.

427 In the omnipresent food Panopticon, we will be able to assess the influence of state428 modulating or state-mediating substances like biogenic amines or neuropeptides and 429 their receptors on locomotion parameters, without interference of foraging-motivated 430 movement. Being able to do this over prolonged periods will help to discern long-lasting 431 pleiotropic effects of these effectors (Martelli et al., 2017; Dreyer et al., 2019; Nässel et al., 2019).

\section{Conflict of Interest}

The authors declare that the research was conducted in the absence of any commercial or financial relationships that could be construed as a potential conflict of interest.

\section{Data availability statement}

439 The 3D .stl-file of the Panopticon and the MATLAB scripts are available on Github under this link: https://github.com/dmahishi/Panopticon.git; the datasets for this study and further details on the Panopticon are available from the authors upon request.

\section{Author contributions}

444 DM, TT, and WH conceived and designed the experiments. DM and RH performed the 445 experiments. DM and TT wrote the MATLAB script. DM, TT and WH analysed the 446 results and wrote the article. All authors provided comments and approved the 447 manuscript. 
$449 \quad$ Funding

450 This work was supported by a grant to WH by the Deutsche Forschungsgemeinschaft

451 (HU2747/1-1) and the Open Access Publication Funds of the University of Leipzig.

452

\section{Acknowledgments}

454 We thank Ingo Kannetzky for expert help with 3D printing and design. We also thank 455 Andreas Thum, Bert Klagges and Kathrin Steck for their support and input on all levels.

456

\section{Supplementary Material}

458 1. 3D-printable .stl file of Panopticon

459 2. FIJl-Macro for tracking

460 3. MATLAB code \& Documentation 
463

464

465

466

467

468

469

470

471

472

473

474

475

476

477

478

479

480

481

482

483

484

485

486

487

488

489

490

491

492

493

494

495

496

497

498

499

500

501

\section{References}

Albin, S. D., Kaun, K. R., Knapp, J.-M., Chung, P., Heberlein, U., and Simpson, J. H. (2015). A Subset of Serotonergic Neurons Evokes Hunger in Adult Drosophila. Current Biology 25, 2435-2440. doi:10.1016/j.cub.2015.08.005.

Barwell, T., Raina, S., and Seroude, L. (2020). Versatile method to measure locomotion in adult Drosophila. Genome, 1-7. doi:10.1139/gen-2020-0044.

Bell, W. J. (1990). Searching Behavior Patterns in Insects. Annu. Rev. Entomol. 35, 447-467. doi:10.1146/annurev.en.35.010190.002311.

Bell, W. J., Cathy, T., Roggero, R. J., Kipp, L. R., and Tobin, T. R. (1985). Sucrose-stimulated searching behaviour of Drosophila melanogaster in a uniform habitat: modulation by period of deprivation. Animal Behaviour 33, 436-448. doi:10.1016/S0003-3472(85)80068-3.

Brockmann, A., Basu, P., Shakeel, M., Murata, S., Murashima, N., Boyapati, R. K., et al. (2018). Sugar Intake Elicits Intelligent Searching Behavior in Flies and Honey Bees. Front. Behav. Neurosci. 12, 280. doi:10.3389/fnbeh.2018.00280.

Burke, C. J., and Waddell, S. (2011). Remembering Nutrient Quality of Sugar in Drosophila. Current Biology 21, 746-750. doi:10.1016/j.cub.2011.03.032.

Burns, J. G., Svetec, N., Rowe, L., Mery, F., Dolan, M. J., Boyce, W. T., et al. (2012). Gene-environment interplay in Drosophila melanogaster: chronic food deprivation in early life affects adult exploratory and fitness traits. Proc. Natl. Acad. Sci. U.S.A. 109 Suppl 2, 17239-17244. doi:10.1073/pnas.1121265109.

Cai, D., Pearce, K., Chen, S., and Glanzman, D. L. (2011). Protein Kinase M Maintains Long-Term Sensitization and Long-Term Facilitation in Aplysia. Journal of Neuroscience 31, 6421-6431. doi:10.1523/JNEUROSCI.4744-10.2011.

Campbell, R. (2020). raacampbell/shadedErrorBar. https://github.com/raacampbell/shadedErrorBar: Github.

Carvalho, G. B., Kapahi, P., and Benzer, S. (2005). Compensatory ingestion upon dietary restriction in Drosophila melanogaster. Nat Methods 2, 813-815. doi:10.1038/nmeth798.

Carvalho-Santos, Z., Cardoso-Figueiredo, R., Elias, A. P., Tastekin, I., Baltazar, C., and Ribeiro, C. (2020). Cellular metabolic reprogramming controls sugar appetite in Drosophila. Nat Metab 2, 958-973. doi:10.1038/s42255-020-0266-x.

Cassel, J.-C. (2010). "Experimental Studies on the Role(s) of Serotonin in Learning and Memory Functions," in Handbook of Behavioral Neuroscience (Elsevier), 429-447. doi:10.1016/S15697339(10)70094-1.

Chouhan, N. S., Griffith, L. C., Haynes, P., and Sehgal, A. (2020). Availability of food determines the need for sleep in memory consolidation. Nature. doi:10.1038/s41586-020-2997-y.

Connolly, K. (1966a). Locomotor activity in Drosophila. II. Selection for active and inactive strains. Animal Behaviour 14, 444-449. doi:10.1016/S0003-3472(66)80043-X.

Connolly, K. J. (1966b). Locomotor Activity in Drosophila as a Function of Food Deprivation. Nature 209, 224-224. doi:10.1038/209224a0. 
502

503

504

505

506

507

508

509

510

511

512

513

514

515

516

517

518

519

520

521

522

523

524

525

526

527

528

529

530

531

532

533

534

535

536

537

538

539

Corfas, R. A., Sharma, T., and Dickinson, M. H. (2019). Diverse Food-Sensing Neurons Trigger Idiothetic Local Search in Drosophila. Current Biology 29, 1660-1668.e4. doi:10.1016/j.cub.2019.03.004.

Corrales-Carvajal, V. M., Faisal, A. A., and Ribeiro, C. (2016). Internal states drive nutrient homeostasis by modulating exploration-exploitation trade-off. eLife 5, e19920. doi:10.7554/eLife.19920.

Davies, L. R., Schou, M. F., Kristensen, T. N., and Loeschcke, V. (2018). Linking developmental diet to adult foraging choice in Drosophila melanogaster. J Exp Biol 221, jeb175554. doi:10.1242/jeb.175554.

Dethier, V. G. (1957). Communication by Insects *. Physiology of Dancini. 125, 6.

Dethier, V. G. (1976). The hungry fly: a physiological study of the behavior associated with feeding. Cambridge, Mass: Harvard University Press.

Donelson, N., Kim, E. Z., Slawson, J. B., Vecsey, C. G., Huber, R., and Griffith, L. C. (2012). High-Resolution Positional Tracking for Long-Term Analysis of Drosophila Sleep and Locomotion Using the "Tracker" Program. PLoS ONE 7, e37250. doi:10.1371/journal.pone.0037250.

Dreyer, A. P., Martin, M. M., Fulgham, C. V., Jabr, D. A., Bai, L., Beshel, J., et al. (2019). A circadian output center controlling feeding:fasting rhythms in Drosophila. PLoS Genet 15, e1008478. doi:10.1371/journal.pgen.1008478.

Duerr, J. S., and Quinn, W. G. (1982). Three Drosophila mutations that block associative learning also affect habituation and sensitization. Proc Natl Acad Sci U S A 79, 3646-3650. doi:10.1073/pnas.79.11.3646.

Dus, M., Min, S., Keene, A. C., Lee, G. Y., and Suh, G. S. B. (2011). Taste-independent detection of the caloric content of sugar in Drosophila. Proc. Natl. Acad. Sci. U.S.A. 108, 11644-11649. doi:10.1073/pnas.1017096108.

Edgecomb, R. S., Harth, C. E., and Schneiderman, A. M. (1994). Regulation of feeding behavior in adult Drosophila melanogaster varies with feeding regime and nutritional state. J Exp Biol 197, 215235.

Engel, J. E., and Wu, C.-F. (2009). Neurogenetic approaches to habituation and dishabituation in Drosophila. Neurobiology of Learning and Memory, 10.

Farhan, A., Gulati, J., Große-Wilde, E., Vogel, H., Hansson, B. S., and Knaden, M. (2013). The CCHamide 1 receptor modulates sensory perception and olfactory behavior in starved Drosophila. Sci Rep 3, 2765. doi:10.1038/srep02765.

Fromm, J. E., and Bell, W. J. (1987). Search orientation of Musca domestica in patches of sucrose drops. Physiol Entomol 12, 297-307. doi:10.1111/j.1365-3032.1987.tb00754.x.

Frost, W. N., Castellucci, V. F., Hawkins, R. D., and Kandel, E. R. (1985). Monosynaptic connections made by the sensory neurons of the gill- and siphon-withdrawal reflex in Aplysia participate in the storage of long-term memory for sensitization. Proceedings of the National Academy of Sciences 82, 8266-8269. doi:10.1073/pnas.82.23.8266.

Fujita, M., and Tanimura, T. (2011). Drosophila Evaluates and Learns the Nutritional Value of Sugars. Current Biology 21, 751-755. doi:10.1016/j.cub.2011.03.058. 
540

541

542

543

544

545

546

547

548

549

550

551

552

553

554

555

556

557

558

559

560

561

562

563

564

565

566

567

568

569

570

571

572

573

574

575

576

577

Gelperin, A. (1971). Abdominal sensory neurons providing negative feedback to the feeding behavior of the blowfly. Z. Vergl. Physiol. 72, 17-31. doi:10.1007/BF00299201.

Green, E. W., O'Callaghan, E. K., Hansen, C. N., Bastianello, S., Bhutani, S., Vanin, S., et al. (2015). Drosophila circadian rhythms in seminatural environments: Summer afternoon component is not an artifact and requires TrpA1 channels. Proc Natl Acad Sci USA 112, 8702-8707. doi:10.1073/pnas.1506093112.

Green, G. W. (1964a). The control of spontaneous locomotor activity in Phormia regina Meigen-I. Locomotor activity patterns of intact flies. Journal of Insect Physiology 10, 711-726. doi:10.1016/0022-1910(64)90054-X.

Green, G. W. (1964b). The control of spontaneous locomotor activity in Phormia regina Meigen-II. Experiments to determine the mechanism involved. Journal of Insect Physiology 10, 727-752. doi:10.1016/0022-1910(64)90055-1.

Grunwald Kadow, I. C. (2019). State-dependent plasticity of innate behavior in fruit flies. Current Opinion in Neurobiology 54, 60-65. doi:10.1016/j.conb.2018.08.014.

Guo, F., Yu, J., Jung, H. J., Abruzzi, K. C., Luo, W., Griffith, L. C., et al. (2016). Circadian neuron feedback controls the Drosophila sleep-activity profile. Nature 536, 292-297. doi:10.1038/nature19097.

Haberkern, H., Basnak, M. A., Ahanonu, B., Schauder, D., Cohen, J. D., Bolstad, M., et al. (2019). Visually Guided Behavior and Optogenetically Induced Learning in Head-Fixed Flies Exploring a Virtual Landscape. Current Biology 29, 1647-1659.e8. doi:10.1016/j.cub.2019.04.033.

Hadjieconomou, D., King, G., Gaspar, P., Mineo, A., Blackie, L., Ameku, T., et al. (2020). Enteric neurons increase maternal food intake during reproduction. Nature 587, 455-459. doi:10.1038/s41586020-2866-8.

Hassett, C. C. (1948). THE UTILIZATION OF SUGARS AND OTHER SUBSTANCES BY DROSOPHILA. The Biological Bulletin 95, 114-123. doi:10.2307/1538158.

Hawkins, R., Abrams, T., Carew, T., and Kandel, E. (1983). A cellular mechanism of classical conditioning in Aplysia: activity-dependent amplification of presynaptic facilitation. Science 219, 400-405. doi:10.1126/science.6294833.

He, J., Hommen, F., Lauer, N., Balmert, S., and Scholz, H. (2020). Serotonin transporter dependent modulation of food-seeking behavior. PLOS ONE 15, e0227554.

doi:10.1371/journal.pone.0227554.

Hirano, Y., Ihara, K., Masuda, T., Yamamoto, T., Iwata, I., Takahashi, A., et al. (2016). Shifting transcriptional machinery is required for long-term memory maintenance and modification in Drosophila mushroom bodies. Nat Commun 7, 13471. doi:10.1038/ncomms13471.

Hirano, Y., Masuda, T., Naganos, S., Matsuno, M., Ueno, K., Miyashita, T., et al. (2013). Fasting launches CRTC to facilitate long-term memory formation in Drosophila. Science 339, 443-446. doi:10.1126/science.1227170.

Hirano, Y., and Saitoe, M. (2013). Hunger and memory; CRTC coordinates long-term memory with the physiological state, hunger. Commun Integr Biol 6, e25152. doi:10.4161/cib.25152. 
578

579

580

581

582

583

584

585

586

587

588

589

590

591

592

593

594

595

596

597

598

599

600

601

602

603

604

605

606

607

608

609

610

611

612

613

614

615

616

617

Howard, C. E., Chen, C.-L., Tabachnik, T., Hormigo, R., Ramdya, P., and Mann, R. S. (2019). Serotonergic Modulation of Walking in Drosophila. Current Biology 29, 4218-4230.e8. doi:10.1016/j.cub.2019.10.042.

Huetteroth, W., Perisse, E., Lin, S., Klappenbach, M., Burke, C., and Waddell, S. (2015). Sweet Taste and Nutrient Value Subdivide Rewarding Dopaminergic Neurons in Drosophila. Current Biology 25, 751-758. doi:10.1016/j.cub.2015.01.036.

Hughson, B. N., Anreiter, I., Jackson Chornenki, N. L., Murphy, K. R., Ja, W. W., Huber, R., et al. (2018). The adult foraging assay (AFA) detects strain and food-deprivation effects in feeding-related traits of Drosophila melanogaster. Journal of Insect Physiology 106, 20-29. doi:10.1016/j.jinsphys.2017.08.011.

Ichinose, T., Aso, Y., Yamagata, N., Abe, A., Rubin, G. M., and Tanimoto, H. (2015). Reward signal in a recurrent circuit drives appetitive long-term memory formation. eLife 4, e10719. doi:10.7554/eLife.10719.

Inagaki, H. K., Panse, K. M., and Anderson, D. J. (2014). Independent, reciprocal neuromodulatory control of sweet and bitter taste sensitivity during starvation in Drosophila. Neuron 84, 806-820. doi:10.1016/j.neuron.2014.09.032.

Itskov, P. M., Moreira, J.-M., Vinnik, E., Lopes, G., Safarik, S., Dickinson, M. H., et al. (2014). Automated monitoring and quantitative analysis of feeding behaviour in Drosophila. Nat Commun 5, 4560. doi:10.1038/ncomms5560.

Joseph, R. M., Devineni, A. V., King, I. F. G., and Heberlein, U. (2009). Oviposition preference for and positional avoidance of acetic acid provide a model for competing behavioral drives in Drosophila. Proceedings of the National Academy of Sciences 106, 11352-11357. doi:10.1073/pnas.0901419106.

Kacsoh, B. Z., Bozler, J., Hodge, S., Ramaswami, M., and Bosco, G. (2015). A Novel Paradigm for Nonassociative Long-Term Memory in Drosophila : Predator-Induced Changes in Oviposition Behavior. Genetics 199, 1143-1157. doi:10.1534/genetics.114.172221.

Khuong, T. M., Wang, Q.-P., Manion, J., Oyston, L. J., Lau, M.-T., Towler, H., et al. (2019). Nerve injury drives a heightened state of vigilance and neuropathic sensitization in Drosophila. Sci. Adv. 5, eaaw4099. doi:10.1126/sciadv.aaw4099.

Kim, I. S., and Dickinson, M. H. (2017). Idiothetic Path Integration in the Fruit Fly Drosophila melanogaster. Current Biology 27, 2227-2238.e3. doi:10.1016/j.cub.2017.06.026.

Knoppien, P., Jan N. C. van der Pers, and van Delden, W. (2000). Quantification of Locomotion and the Effect of Food Deprivation on Locomotor Activity in Drosophila. Journal of Insect Behavior 13, 27-43.

König, C., Antwi-Adjei, E., Ganesan, M., Kilonzo, K., Viswanathan, V., Durairaja, A., et al. (2017). Aversive olfactory associative memory loses odor specificity over time. J Exp Biol 220, 1548-1553. doi:10.1242/jeb.155317.

Krashes, M. J., and Waddell, S. (2008). Rapid Consolidation to a radish and Protein Synthesis-Dependent Long-Term Memory after Single-Session Appetitive Olfactory Conditioning in Drosophila. Journal of Neuroscience 28, 3103-3113. doi:10.1523/JNEUROSCI.5333-07.2008. 
618

619

620

621

622

623

624

625

626

627

628

629

630

631

632

633

634

635

636

637

638

639

640

641

642

643

644

645

646

647

648

649

650

651

652

653

654

655

Landayan, D., Feldman, D. S., and Wolf, F. W. (2018). Satiation state-dependent dopaminergic control of foraging in Drosophila. Sci Rep 8, 5777. doi:10.1038/s41598-018-24217-1.

Lee, K. P., Simpson, S. J., Clissold, F. J., Brooks, R., Ballard, J. W. O., Taylor, P. W., et al. (2008). Lifespan and reproduction in Drosophila: New insights from nutritional geometry. Proceedings of the National Academy of Sciences 105, 2498-2503. doi:10.1073/pnas.0710787105.

Lim, R. S., Eyjólfsdóttir, E., Shin, E., Perona, P., and Anderson, D. J. (2014). How Food Controls Aggression in Drosophila. PLoS ONE 9, e105626. doi:10.1371/journal.pone.0105626.

Lin, S., Senapati, B., and Tsao, C.-H. (2019). Neural basis of hunger-driven behaviour in Drosophila. Open Biol. 9, 180259. doi:10.1098/rsob.180259.

Liu, C., Meng, Z., Wiggin, T. D., Yu, J., Reed, M. L., Guo, F., et al. (2019). A Serotonin-Modulated Circuit Controls Sleep Architecture to Regulate Cognitive Function Independent of Total Sleep in Drosophila. Current Biology 29, 3635-3646.e5. doi:10.1016/j.cub.2019.08.079.

Liu, G., Seiler, H., Wen, A., Zars, T., Ito, K., Wolf, R., et al. (2006). Distinct memory traces for two visual features in the Drosophila brain. Nature 439, 551-556. doi:10.1038/nature04381.

Liu, Y., Luo, J., Carlsson, M. A., and Nässel, D. R. (2015). Serotonin and insulin-like peptides modulate leucokinin-producing neurons that affect feeding and water homeostasis in Drosophila: Modulation of LK Neurons in Drosophila. Journal of Comparative Neurology 523, 1840-1863. doi:10.1002/cne.23768.

Longden, K. D., Muzzu, T., Cook, D. J., Schultz, S. R., and Krapp, H. G. (2014). Nutritional State Modulates the Neural Processing of Visual Motion. Current Biology 24, 890-895. doi:10.1016/j.cub.2014.03.005.

Mahishi, D., and Huetteroth, W. (2019). The prandial process in flies. Current Opinion in Insect Science 36, 157-166. doi:10.1016/j.cois.2019.09.004.

Mann, K., Gordon, M. D., and Scott, K. (2013). A Pair of Interneurons Influences the Choice between Feeding and Locomotion in Drosophila. Neuron 79, 754-765. doi:10.1016/j.neuron.2013.06.018.

Martelli, C., Pech, U., Kobbenbring, S., Pauls, D., Bahl, B., Sommer, M. V., et al. (2017). SIFamide Translates Hunger Signals into Appetitive and Feeding Behavior in Drosophila. Cell Reports 20, 464-478. doi:10.1016/j.celrep.2017.06.043.

Martin, J.-R. (2004). A portrait of locomotor behaviour in Drosophila determined by a video-tracking paradigm. Behavioural Processes 67, 207-219. doi:10.1016/j.beproc.2004.04.003.

May, C. E., Rosander, J., Gottfried, J., Dennis, E., and Dus, M. (2020). Dietary sugar inhibits satiation by decreasing the central processing of sweet taste. elife 9, e54530. doi:10.7554/eLife.54530.

May, C. E., Vaziri, A., Lin, Y. Q., Grushko, O., Khabiri, M., Wang, Q.-P., et al. (2019). High Dietary Sugar Reshapes Sweet Taste to Promote Feeding Behavior in Drosophila melanogaster. Cell Reports 27, 1675-1685.e7. doi:10.1016/j.celrep.2019.04.027.

Meunier, N., Belgacem, Y. H., and Martin, J.-R. (2007). Regulation of feeding behaviour and locomotor activity by takeout in Drosophila. Journal of Experimental Biology 210, 1424-1434. doi:10.1242/jeb.02755. 
656

657

658

659

660

661

662

663

664

665

666

667

668

669

670

671

672

673

674

675

676

677

678

679

680

681

682

683

684

685

686

687

688

689

690

691

692

693

Min, S., Oh, Y., Verma, P., Van Vactor, D., Suh, G. S. B., and Liberles, S. D. (2020). Control of feeding by Piezo-mediated gut mechanosensation in Drosophila. Neuroscience doi:10.1101/2020.09.11.293712.

Moreira, J.-M., Itskov, P. M., Goldschmidt, D., Baltazar, C., Steck, K., Tastekin, I., et al. (2019). optoPAD, a closed-loop optogenetics system to study the circuit basis of feeding behaviors. elife 8, e43924. doi:10.7554/eLife.43924.

Murata, S., Brockmann, A., and Tanimura, T. (2017). Pharyngeal stimulation with sugar triggers local searching behavior in Drosophila. J Exp Biol 220, 3231-3237. doi:10.1242/jeb.161646.

Murphy, K. R., Deshpande, S. A., Yurgel, M. E., Quinn, J. P., Weissbach, J. L., Keene, A. C., et al. (2016). Postprandial sleep mechanics in Drosophila. eLife 5, e19334. doi:10.7554/eLife.19334.

Musso, P.-Y., Junca, P., Jelen, M., Feldman-Kiss, D., Zhang, H., Chan, R. C., et al. (2019). Closed-loop optogenetic activation of peripheral or central neurons modulates feeding in freely moving Drosophila. elife 8, e45636. doi:10.7554/eLife.45636.

Musso, P.-Y., Lampin-Saint-Amaux, A., Tchenio, P., and Preat, T. (2017). Ingestion of artificial sweeteners leads to caloric frustration memory in Drosophila. Nat Commun 8, 1803. doi:10.1038/s41467017-01989-0.

Musso, P.-Y., Tchenio, P., and Preat, T. (2015). Delayed Dopamine Signaling of Energy Level Builds Appetitive Long-Term Memory in Drosophila. Cell Reports 10, 1023-1031. doi:10.1016/j.celrep.2015.01.036.

Nässel, D. R., Pauls, D., and Huetteroth, W. (2019). Neuropeptides in modulation of Drosophila behavior: how to get a grip on their pleiotropic actions. Current Opinion in Insect Science 36, 1-8. doi:10.1016/j.cois.2019.03.002.

Navawongse, R., Choudhury, D., Raczkowska, M., Stewart, J. C., Lim, T., Rahman, M., et al. (2016). Drosophila learn efficient paths to a food source. Neurobiology of Learning and Memory 131, 176-181. doi:10.1016/j.nlm.2016.03.019.

Neuser, K., Triphan, T., Mronz, M., Poeck, B., and Strauss, R. (2008). Analysis of a spatial orientation memory in Drosophila. Nature 453, 1244-1247. doi:10.1038/nature07003.

Nishimura, A., Ishida, Y., Takahashi, A., Okamoto, H., Sakabe, M., Itoh, M., et al. (2012). StarvationInduced Elevation of Taste Responsiveness and Expression of a Sugar Taste Receptor Gene in Drosophila melanogaster. Journal of Neurogenetics 26, 206-215. doi:10.3109/01677063.2012.694931.

Ofstad, T. A., Zuker, C. S., and Reiser, M. B. (2011). Visual place learning in Drosophila melanogaster. Nature 474, 204-207. doi:10.1038/nature10131.

Paranjpe, P., Rodrigues, V., VijayRaghavan, K., and Ramaswami, M. (2012). Gustatory habituation in Drosophila relies on rutabaga (adenylate cyclase)-dependent plasticity of GABAergic inhibitory neurons. Learning \& Memory 19, 627-635. doi:10.1101/Im.026641.112.

Park, J. H., Carvalho, G. B., Murphy, K. R., Ehrlich, M. R., and Ja, W. W. (2017). Sucralose Suppresses Food Intake. Cell Metabolism 25, 484-485. doi:10.1016/j.cmet.2017.02.011. 
694

695

696

697

698

699

700

701

702

703

704

705

706

707

708

709

710

711

712

713

714

715

716

717

718

719

720

721

722

723

724

725

726

727

728

729

730

731

732

733

Pauls, D., Selcho, M., Räderscheidt, J., Amatobi, K., Fekete, A., Krischke, M., et al. (2020). Endocrine finetuning of daily locomotor activity patterns under non-starving conditions in Drosophila. Neuroscience doi:10.1101/2020.02.13.947556.

Pegoraro, M., Flavell, L. M. M., Menegazzi, P., Colombi, P., Dao, P., Helfrich-Förster, C., et al. (2020). The genetic basis of diurnal preference in Drosophila melanogaster. BMC Genomics 21, 596. doi:10.1186/s12864-020-07020-z.

Pereira, H. S., and Sokolowski, M. B. (1993). Mutations in the larval foraging gene affect adult locomotory behavior after feeding in Drosophila melanogaster. Proceedings of the National Academy of Sciences 90, 5044-5046. doi:10.1073/pnas.90.11.5044.

Pinsker, H. M., Hening, W. A., Carew, T. J., and Kandel, E. R. (1973). Long-Term Sensitization of a Defensive Withdrawal Reflex in Aplysia. Science 182, 1039-1042. doi:10.1126/science.182.4116.1039.

Plaçais, P.-Y., de Tredern, É., Scheunemann, L., Trannoy, S., Goguel, V., Han, K.-A., et al. (2017). Upregulated energy metabolism in the Drosophila mushroom body is the trigger for long-term memory. Nat Commun 8, 15510. doi:10.1038/ncomms15510.

Pooryasin, A., and Fiala, A. (2015). Identified Serotonin-Releasing Neurons Induce Behavioral Quiescence and Suppress Mating in Drosophila. Journal of Neuroscience 35, 12792-12812. doi:10.1523/JNEUROSCI.1638-15.2015.

Ribeiro, C., and Dickson, B. J. (2010). Sex Peptide Receptor and Neuronal TOR/S6K Signaling Modulate Nutrient Balancing in Drosophila. Current Biology 20, 1000-1005. doi:10.1016/j.cub.2010.03.061.

Ries, A.-S., Hermanns, T., Poeck, B., and Strauss, R. (2017). Serotonin modulates a depression-like state in Drosophila responsive to lithium treatment. Nat Commun 8, 15738. doi:10.1038/ncomms15738.

Robie, A. A., Straw, A. D., and Dickinson, M. H. (2010). Object preference by walking fruit flies, Drosophila melanogaster, is mediated by vision and graviperception. Journal of Experimental Biology 213, 2494-2506. doi:10.1242/jeb.041749.

Root, C. M., Ko, K. I., Jafari, A., and Wang, J. W. (2011). Presynaptic Facilitation by Neuropeptide Signaling Mediates Odor-Driven Food Search. Cell 145, 133-144. doi:10.1016/j.cell.2011.02.008.

Sachse, S., and Beshel, J. (2016). The good, the bad, and the hungry: how the central brain codes odor valence to facilitate food approach in Drosophila. Current Opinion in Neurobiology 40, 53-58. doi:10.1016/j.conb.2016.06.012.

Sayin, S., De Backer, J.-F., Siju, K. P., Wosniack, M. E., Lewis, L. P., Frisch, L.-M., et al. (2019). A Neural Circuit Arbitrates between Persistence and Withdrawal in Hungry Drosophila. Neuron 104, 544558.e6. doi:10.1016/j.neuron.2019.07.028.

Scheiner, R. (2004). Activity of cGMP-Dependent Protein Kinase (PKG) Affects Sucrose Responsiveness and Habituation in Drosophila melanogaster. Learning \& Memory 11, 303-311. doi:10.1101/Im.71604.

Schützler, N., Girwert, C., Hügli, I., Mohana, G., Roignant, J.-Y., Ryglewski, S., et al. (2019). Tyramine action on motoneuron excitability and adaptable tyramine/octopamine ratios adjust Drosophila 
locomotion to nutritional state. Proc Natl Acad Sci USA 116, 3805-3810. doi:10.1073/pnas.1813554116.

Seidenbecher, S. E., Sanders, J. I., von Philipsborn, A. C., and Kvitsiani, D. (2020). Reward foraging task and model-based analysis reveal how fruit flies learn value of available options. PLOS ONE 15, e0239616. doi:10.1371/journal.pone.0239616.

Selcho, M., and Pauls, D. (2019). Linking physiological processes and feeding behaviors by octopamine. Current Opinion in Insect Science 36, 125-130. doi:10.1016/j.cois.2019.09.002.

Sitaraman, D., Kramer, E. F., Kahsai, L., Ostrowski, D., and Zars, T. (2017). Discrete Serotonin Systems Mediate Memory Enhancement and Escape Latencies after Unpredicted Aversive Experience in Drosophila Place Memory. Front. Syst. Neurosci. 11, 92. doi:10.3389/fnsys.2017.00092.

Sitaraman, D., and LaFerriere, H. (2020). Finding a place and leaving a mark in memory formation. Journal of Neurogenetics 34, 21-27. doi:10.1080/01677063.2019.1706094.

Sitaraman, D., Zars, M., LaFerriere, H., Chen, Y.-C., Sable-Smith, A., Kitamoto, T., et al. (2008). Serotonin is necessary for place memory in Drosophila. Proceedings of the National Academy of Sciences 105, 5579-5584. doi:10.1073/pnas.0710168105.

Sitaraman, D., and Zars, T. (2010). Lack of prediction for high-temperature exposures enhances Drosophila place learning. Journal of Experimental Biology 213, 4018-4022. doi:10.1242/jeb.050344.

Soibam, B., Mann, M., Liu, L., Tran, J., Lobaina, M., Kang, Y. Y., et al. (2012). Open-field arena boundary is a primary object of exploration for Drosophila. Brain and Behavior 2, 97-108. doi:10.1002/brb3.36.

Stafford, J. W., Lynd, K. M., Jung, A. Y., and Gordon, M. D. (2012). Integration of Taste and Calorie Sensing in Drosophila. Journal of Neuroscience 32, 14767-14774. doi:10.1523/JNEUROSCI.188712.2012 .

Stam, R. (2007). PTSD and stress sensitisation: A tale of brain and body Part 2: Animal models. Neuroscience \& Biobehavioral Reviews 31, 558-584. doi:10.1016/j.neubiorev.2007.01.001.

Stern, U., Srivastava, H., Chen, H.-L., Mohammad, F., Claridge-Chang, A., and Yang, C.-H. (2019). Learning a Spatial Task by Trial and Error in Drosophila. Current Biology 29, 2517-2525.e5. doi:10.1016/j.cub.2019.06.045.

Tatar, M., Post, S., and Yu, K. (2014). Nutrient control of Drosophila longevity. Trends in Endocrinology \& Metabolism 25, 509-517. doi:10.1016/j.tem.2014.02.006.

Tierney, A. J. (2020). Feeding, hunger, satiety and serotonin in invertebrates. Proc. R. Soc. B. 287, 20201386. doi:10.1098/rspb.2020.1386.

Tsao, C.-H., Chen, C.-C., Lin, C.-H., Yang, H.-Y., and Lin, S. (2018). Drosophila mushroom bodies integrate hunger and satiety signals to control innate food-seeking behavior. eLife 7, e35264. doi:10.7554/eLife.35264.

Vaziri, A., Khabiri, M., Genaw, B. T., May, C. E., Freddolino, P. L., and Dus, M. (2020). Persistent Epigenetic Reprogramming of Sweet Taste by Diet. Neuroscience doi:10.1101/2020.03.25.007773. 
773

774

775

776

777

778

779

780

781

782

783

784

785

786

787

788

789

790

791

792

793

794

795

796

797

798

799

800

801

802

803

804
Wang, G., and Wang, L. (2019). Recent advances in the neural regulation of feeding behavior in adult Drosophila. J. Zhejiang Univ. Sci. B 20, 541-549. doi:10.1631/jzus.B1900080.

Wang, P., Jia, Y., Liu, T., Jan, Y.-N., and Zhang, W. (2020a). Visceral Mechano-sensing Neurons Control Drosophila Feeding by Using Piezo as a Sensor. Neuron 108, 640-650.e4. doi:10.1016/j.neuron.2020.08.017.

Wang, Q.-P., Lin, Y. Q., Lai, M.-L., Su, Z., Oyston, L. J., Clark, T., et al. (2020b). PGC1 $\alpha$ Controls Sucrose Taste Sensitization in Drosophila. Cell Reports 31, 107480. doi:10.1016/j.celrep.2020.03.044.

Wang, Q.-P., Lin, Y. Q., Zhang, L., Wilson, Y. A., Oyston, L. J., Cotterell, J., et al. (2016). Sucralose Promotes Food Intake through NPY and a Neuronal Fasting Response. Cell Metabolism 24, 7590. doi:10.1016/j.cmet.2016.06.010.

Wang, Q.-P., Simpson, S. J., Herzog, H., and Neely, G. G. (2017). Chronic Sucralose or L-Glucose Ingestion Does Not Suppress Food Intake. Cell Metabolism 26, 279-280. doi:10.1016/j.cmet.2017.07.002.

Wu, C.-L., Chang, C.-C., Wu, J.-K., Chiang, M.-H., Yang, C.-H., and Chiang, H.-C. (2018). Mushroom body glycolysis is required for olfactory memory in Drosophila. Neurobiology of Learning and Memory 150, 13-19. doi:10.1016/j.nIm.2018.02.015.

Yamagata, N., Ichinose, T., Aso, Y., Plaçais, P.-Y., Friedrich, A. B., Sima, R. J., et al. (2015). Distinct dopamine neurons mediate reward signals for short- and long-term memories. Proc Natl Acad Sci USA 112, 578-583. doi:10.1073/pnas.1421930112.

Yang, Z., Yu, Y., Zhang, V., Tian, Y., Qi, W., and Wang, L. (2015). Octopamine mediates starvation-induced hyperactivity in adult Drosophila. Proceedings of the National Academy of Sciences 112, 52195224. doi:10.1073/pnas.1417838112.

Yellman, C., Tao, H., He, B., and Hirsh, J. (1997). Conserved and sexually dimorphic behavioral responses to biogenic amines in decapitated Drosophila. Proceedings of the National Academy of Sciences 94, 4131-4136. doi:10.1073/pnas.94.8.4131.

Youn, H., Kirkhart, C., Chia, J., and Scott, K. (2018). A subset of octopaminergic neurons that promotes feeding initiation in Drosophila melanogaster. PLOS ONE 13, e0198362. doi:10.1371/journal.pone.0198362.

Zhang, Y., Liu, G., Yan, J., Zhang, Y., Li, B., and Cai, D. (2015). Metabolic learning and memory formation by the brain influence systemic metabolic homeostasis. Nature Communications 6, 6704. doi:10.1038/ncomms7704. 
805

806

807

808

809

810

811

812

813

814

815

816

817

818

819

820

821

822

823

824

825

826

827

828

829

830

831

832

833

834

835

836

\section{Figure 1: The Panopticon}

(A) Entire recording setup for the Panopticon. The whole assay platform has an infrared light source placed in the bottom (grey box with red LEDs), on top of which is a heightadjustable transparent glass platform with a small circular plastic layer acting as as diffusor. The arena itself is placed on this platform, positioned precisely in line with the light source, the diffusor and the recording camera fitted on top with a stable holder. (B) Top view of Panopticon, sagittal view below. The arena consists of eight sectors, as indicated by sector-dividing walls of the 3D printed inset (black), which sits in substrate (blue) inside a Petri dish lid (gray). Another Petri dish lid with a layer of substrate closes the arena. Two configurations are used: i) food patch arena with $1 \%$ agarose as substrate (depicted), which contains individual, centrally located food patch containers (teal blue) filled with $1 \%$ agarose with $200 \mathrm{mM}$ sucrose (pastel pink), or ii) omnipresent food arena without food patches, but $1 \%$ agarose with $200 \mathrm{mM}$ sucrose as substrate (not shown).

\section{Figure 2: Data handling and workflow}

Data acquisition (i) steps with the Panopticon involve preparation of the arena with substrate media, collection and loading of single flies in each of the sectors, followed by recording of fly activity. Further processing and tracking (ii) of recorded data (in JPEG format) is performed on FIJI to further divide collected frames into batches to facilitate efficient image processing and subsequent detection of fly positions. Data analysis (iii) was executed in MATLAB and consisted of pre-processing and quality checks followed by in-depth analysis and plotting of the tracked data (saved and loaded as .csv files).

\section{Figure 3: Starved flies show higher activity and food intake within first $\mathbf{3 0}$ min}

(A) Both fed (deep purple) and starved (orange) flies exhibit raised activity on the food patch assay (inset schematic) during the first $30 \mathrm{~min}$, with starved flies showing significantly higher activity than fed flies. Both groups reach baseline levels in the following $30 \mathrm{~min}$. Data is presented as means \pm s.e.m in 5 min bins. $\mathrm{N}$ values are given in brackets. (B) Initially starved flies make significantly more stops of 2-7 s duration than fed flies in the first $30 \mathrm{~min}$, (C) but not in the next $30 \mathrm{~min}$ on the food patch (inset schematic). (D) Feeding rate, as measured on the flyPAD, indicates that initially starved 
837 flies show higher sip rate in the first 30 min than the fed flies, (E) but decreases to 838 comparable sip rate in the next $30 \mathrm{~min}$. * indicate significance levels following pairwise 839 comparison or 2-way ANOVA tests (alpha = 0.05). Horizontal lines represent 840 comparison between fed and pre-starved flies from a single group. Curly braces represent identical significance levels across multiple groups.

Figure 4: Locomotion activity and food patch preference over $24 \mathrm{~h}$ on food patch assay

845

846

(A) Although initial activity levels on the food patch arena (inset schematic) are comparable, pre-starved flies (orange, $\mathrm{n}=34$ ) continued to show significantly decreased activity levels during subjective evening and early night, as compared to fed flies (deep purple, $n=29$ ). Subjective night indicated by grey-shaded area. There was no significant difference in activity across the rest of the $24 \mathrm{~h}$. (B) Fed flies showed significantly increased numbers of stops of shorter duration (2-7s) on the food patch (inset schematic) than pre-starved flies during peak activity time window of 19:00-19:30, (C) whereas no significant difference in food patch stops was observed between 08:3009:00 the next morning between the two groups. X-axis tick labels indicate duration of stops with a $\log 2$ scale, where $2^{1}=2-3 s, 2^{2}=4-7 s$ and so on. (D) On the food patch (inset schematic) there was no significant difference observed in short-distance moves $(\leq 2 \mathrm{~mm}$ ) between both groups during the 19:00-19:30 time window and (E) during the 08:30-09:00 time window. (F) Pre-starved flies spent significantly higher fractions of time on the food patch (inset schematic) as compared to fed flies, with exception of the initial $3 \mathrm{~h}$. * indicate significance levels following pairwise comparison or 2-way ANOVA tests (alpha $=0.05)$. Horizontal lines indicate significance levels between fed and prestarved flies from a single group. Curly braces represent identical significance levels between fed and pre-starved from multiple groups. $\mathrm{N}$ values are given in brackets.

\section{Figure 5: Initially starved flies show more frequent short walks over 24 h}

(A) Higher probability of short-distance walks $(\leq 2 \mathrm{~mm})$ was observed in pre-starved flies (orange) as compared to fed flies (deep purple) within the entire arena (including food patch area, inset schematic) across $24 \mathrm{~h}$. (B) The significantly increased shortdistance moves for pre-starved flies than those of fed flies were even more pronounced 
869 if analysed on the food patch only (inset schematic) (C) Probability of flies showing 0.1-

$8702 \mathrm{~mm}$ movements were not significantly different between the two groups as observed

871 in the area outside of the food patch (inset schematic). * indicate significance levels

872 following pairwise comparison tests with Bonferroni - Dunn's correction (alpha $=0.05$ ).

873

874 Figure 6: Omnipresent food provision equalises activity levels but not speed

875 (A) Starved (orange, $n=27$ ) and fed flies (deep purple, $n=34$ ) show no significant 876 difference in activity across the first hour on a homogenous sucrose-covered arena

877 (inset schematic), (B) together with no significant differences observed for shorter stops 878 (2-7s). X-axis tick labels indicate duration of stops with a log2 scale, where $2^{1}=2-3 \mathrm{~s}, 2^{2}$ $879=4-7$ s and so on. (C) However, starved flies did show higher frequency of short feeding880 related walks $(0-2 \mathrm{~mm})$ in the first $30 \mathrm{~min}$ than those of fed flies, while fed flies showed a 881 significantly higher frequency of longer distance walks (5-10 mm). (D) There was no 882 significant difference observed again in the next 30 min for shorter stops (2-7s) between 883 the two fly groups, but (E) pre-starved flies continued to show significantly increased 884 short-distance moves as compared to fed flies. (F) Pre-starved flies show comparable 885 activity levels to fed flies, including during the evening activity peak, with no significant 886 difference observed across the remaining $24 \mathrm{~h}$. (G) Location probability within virtual 887 food patch-sized areas revealed no significant difference in place preference across 24 $888 \mathrm{~h}$ for both pre-starved and fed flies. (H) During the 19:00-19:30 time window, both 889 groups showed equal number of short stops (2-7s), with (I) consistent higher frequency 890 of short-distance walks seen in pre-starved flies than fed flies. (J) No significant 891 difference in short stops (2-7s) was observed during the 08:30-09:00 time window the 892 next morning across both groups, (K) and again a significant difference in short893 distance moves. Data indicates higher walking speed in fed flies as compared to pre894 starved flies. * indicate significance levels following pairwise comparison or 2-way 895 ANOVA tests (alpha $=0.05)$.

898 (A) Temporal distribution of failed/missed detections with total error rate (\%) 899 indicated on the right panel for individual flies/sectors across $24 \mathrm{~h}$. (B) Walking path 900 traces for the entire arena divided by sectors, with (C) 3D representation, expandable 
901 on the Z-axis representing walking traces across the total duration of activity recording

902 for 24 h. Time scales represented as frame numbers (@ 1 frame/sec). Blue-yellow-red

903 colour transition represents walking traces from 0-n frame count (across total duration of

904 the experiment). (D) To visually identify long-distance movements associated with

905 potentially false-positive detections, corresponding images for top ten frames with flies

906 covering the longest distances can be extracted (example image for Sector 8). Such

907 images include up to 2 consecutive long distance moves as indicated by individually

908 coloured walking trace lines and the fly itself encircled with the respective colour. Apart

909 from the queried sector, all the other sectors also indicate distances moves in

910 corresponding frames. 


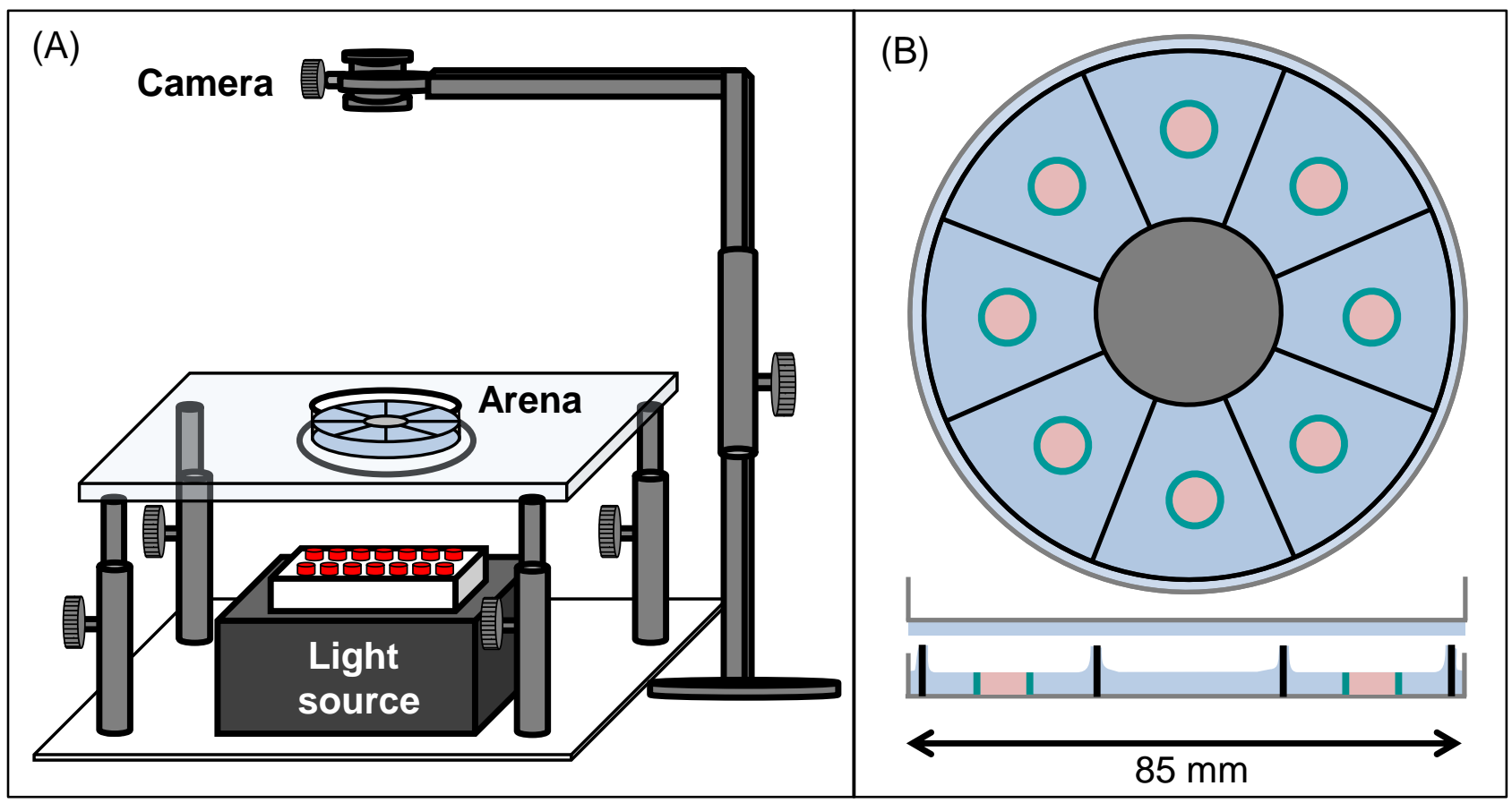

Figure 1 

available under aCC-BY-NC-ND 4.0 International license.

(i)

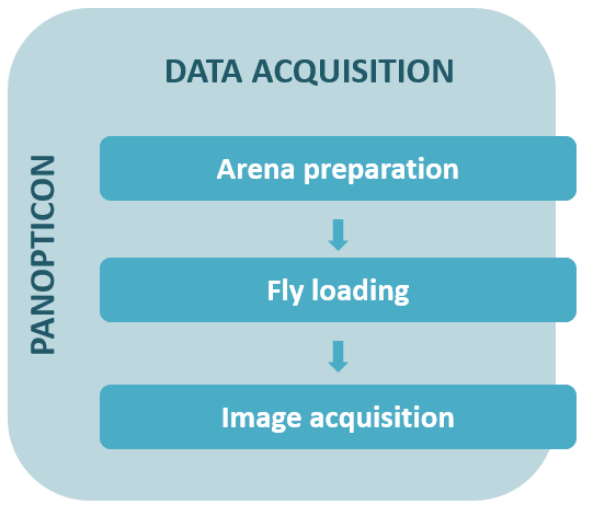

(ii)

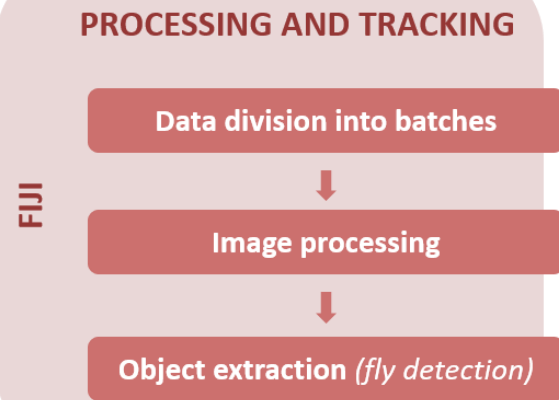

(ii)

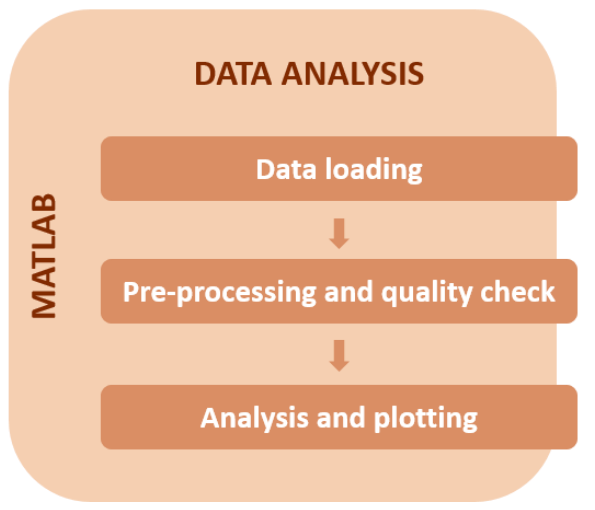

Figure 2 


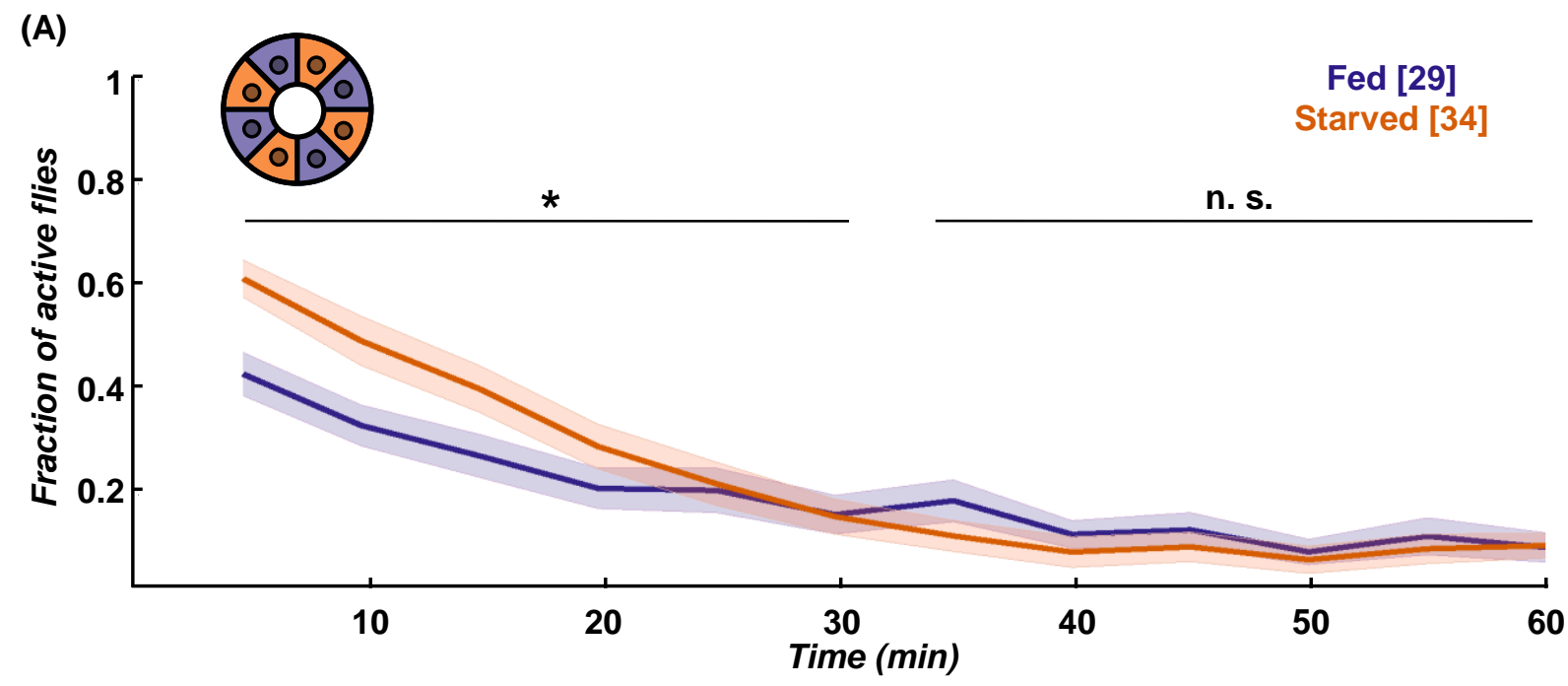

$0-30 \mathrm{~min}$

$31-60 \mathrm{~min}$

(B)

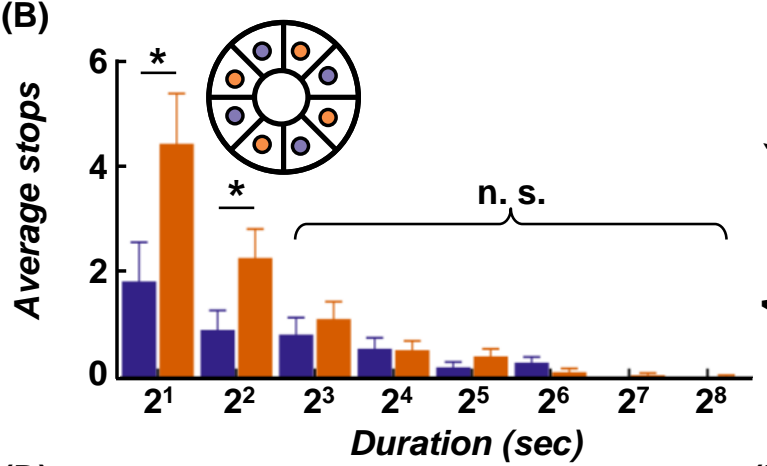

(D)

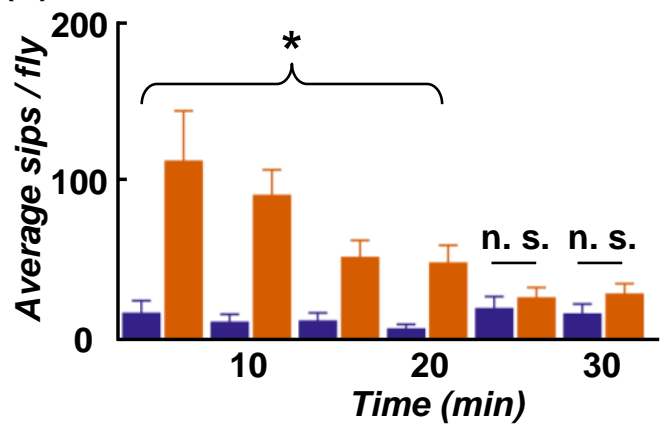

(C)

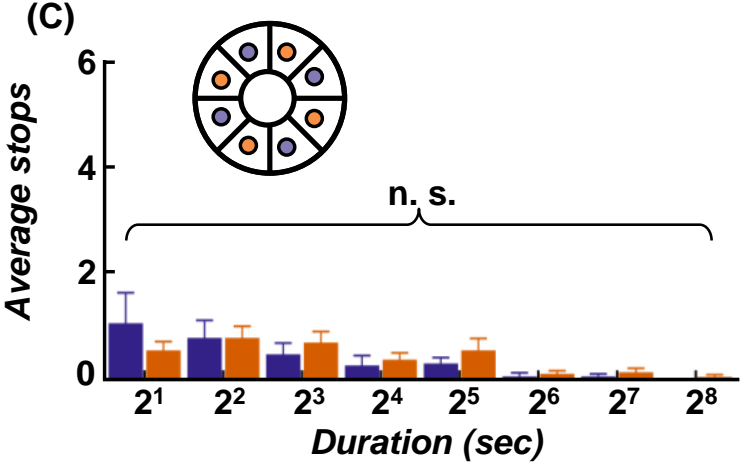

(E)

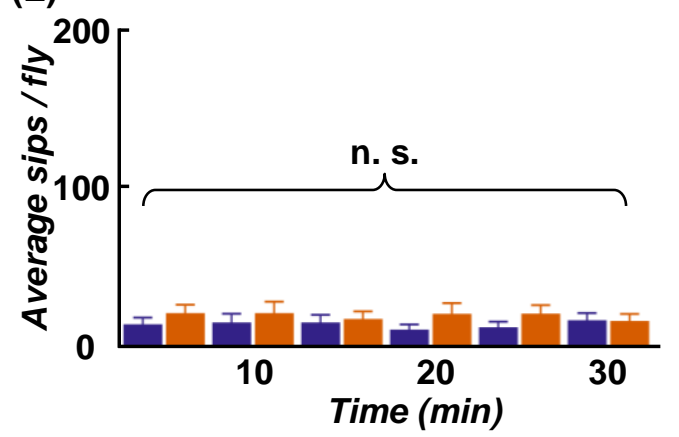

Figure 3 


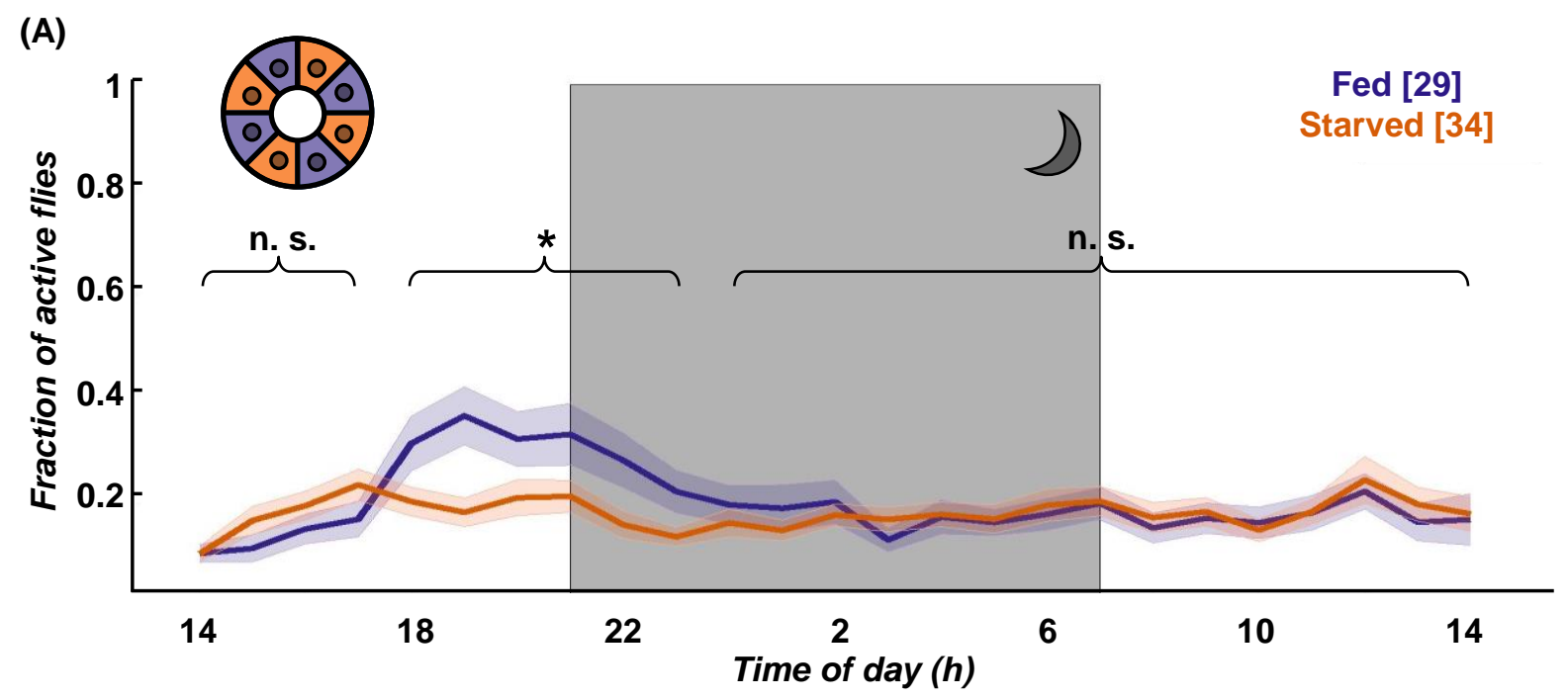

$19: 00-19: 30$

08:30 - 09:00

(B)

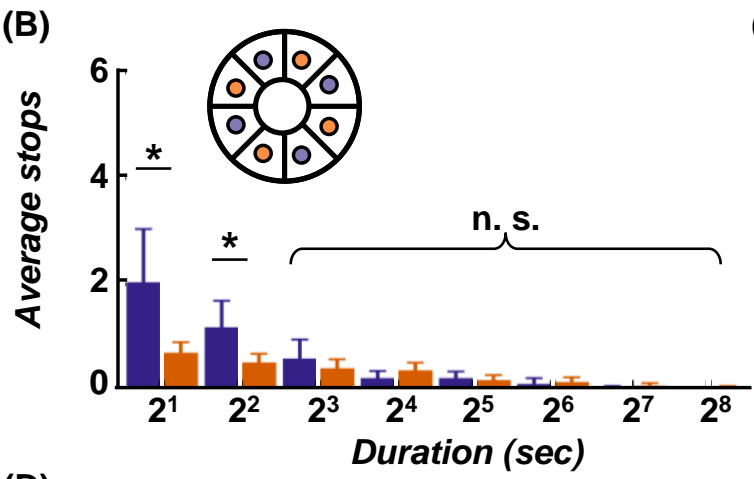

(D)

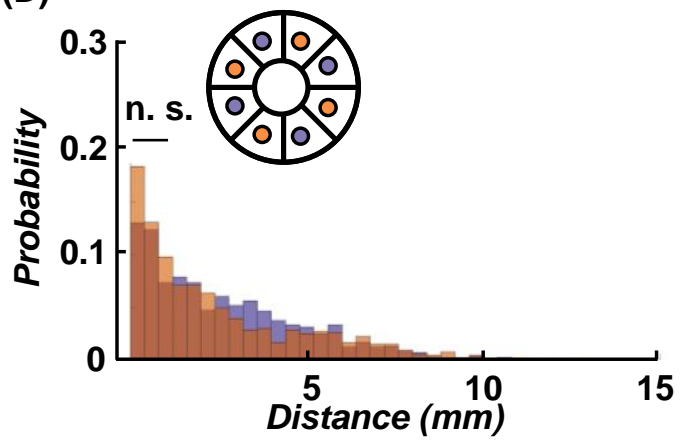

(F)
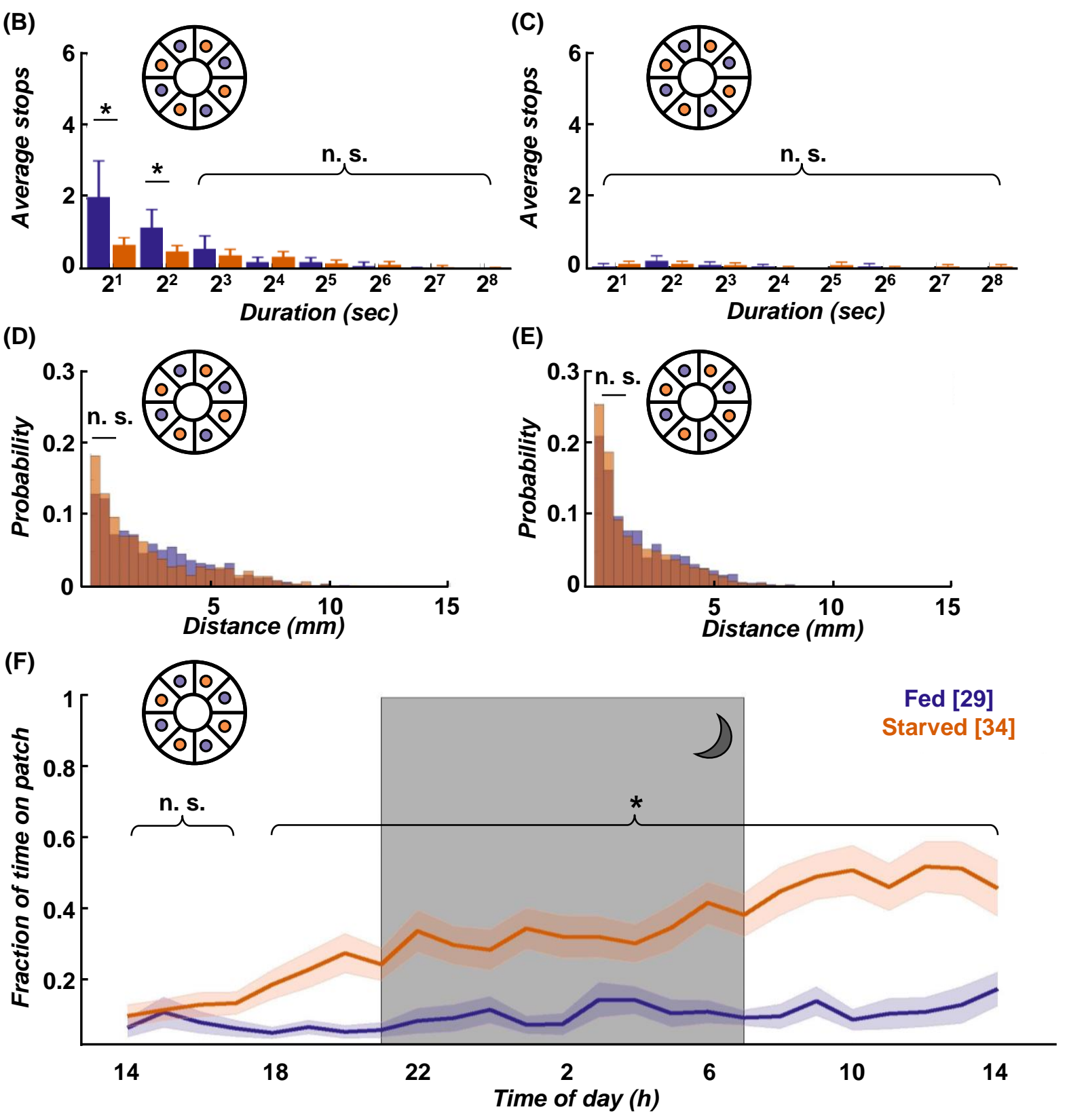

(E)

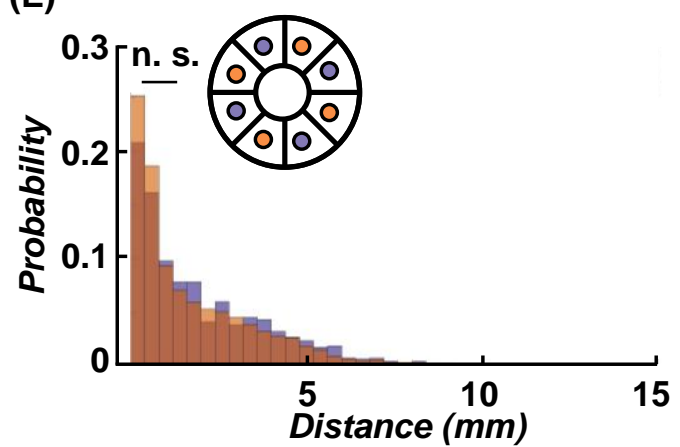

Figure 4 


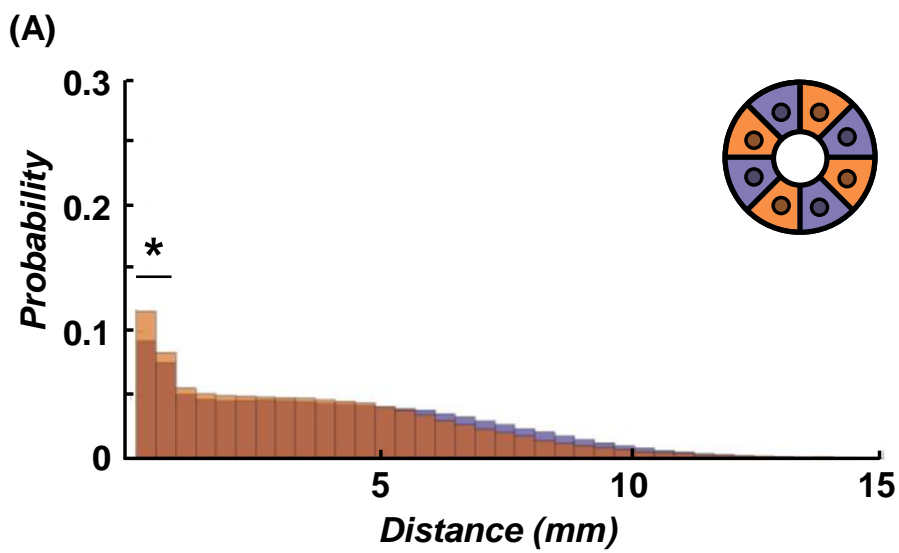

(B)

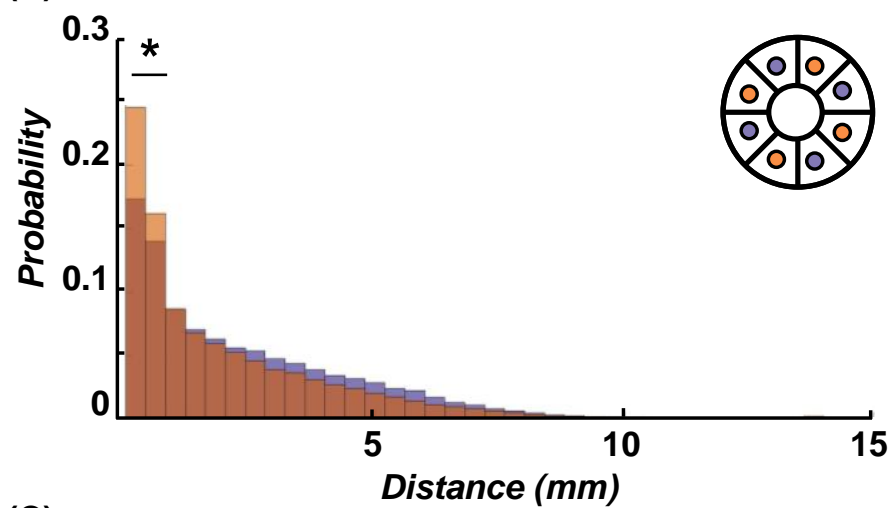

(C)

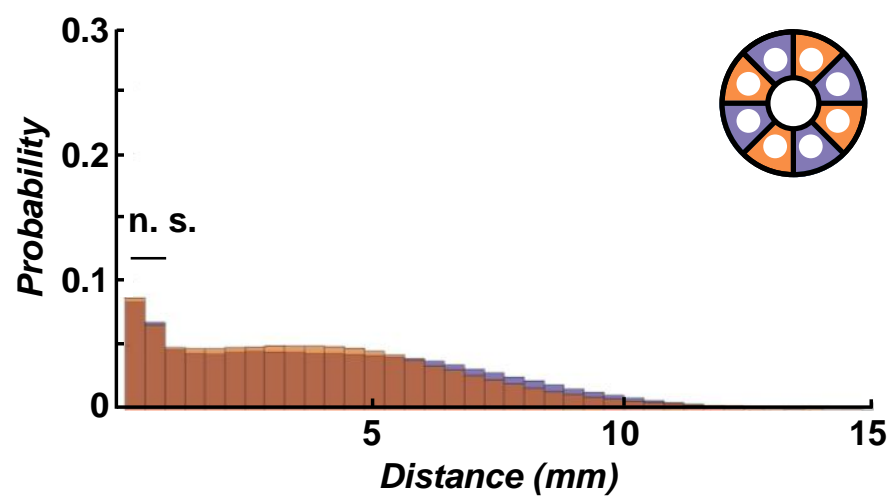

Figure 5 


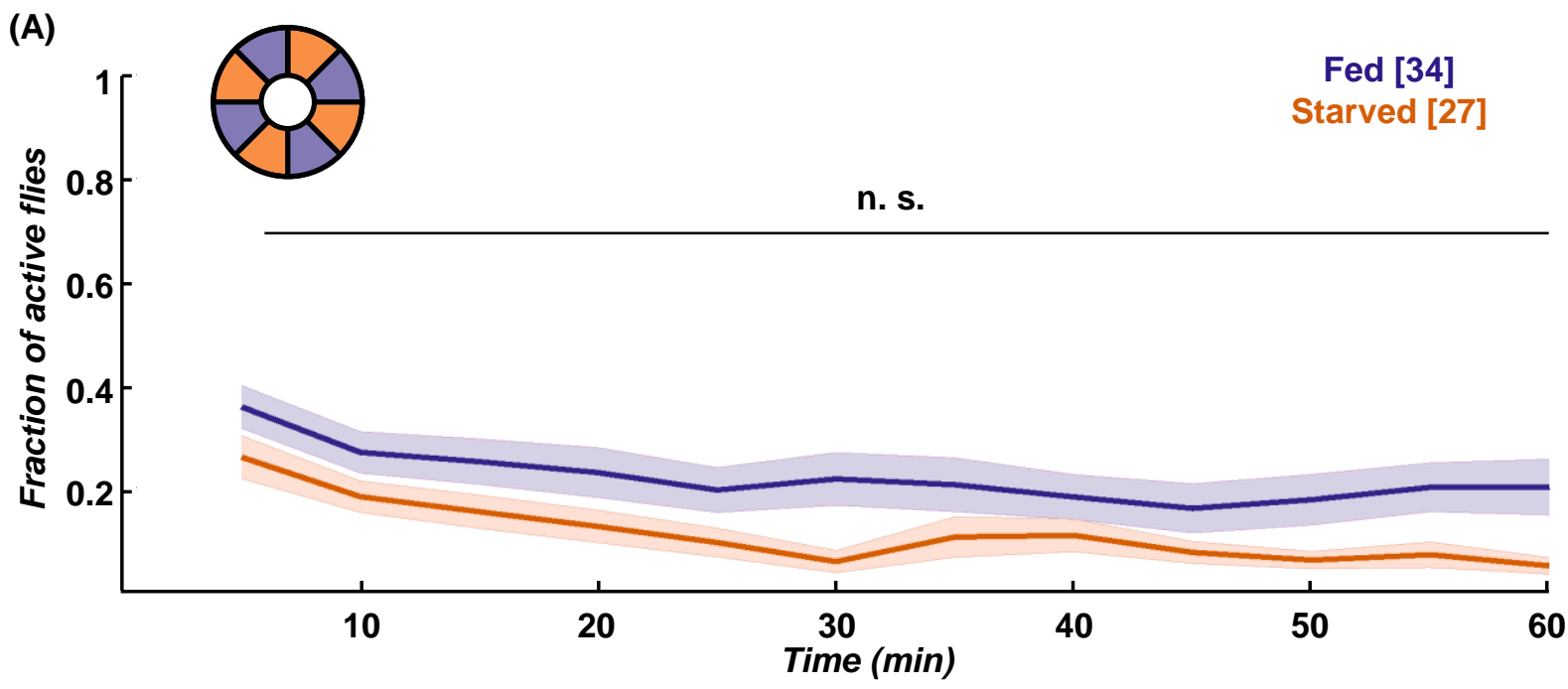

$0-30 \mathrm{~min}$

(B)

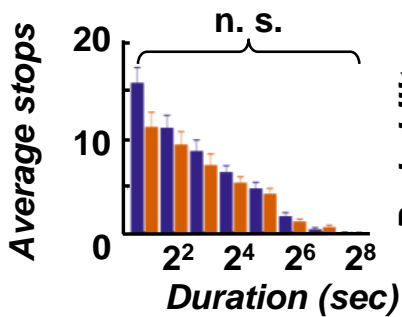

(F)

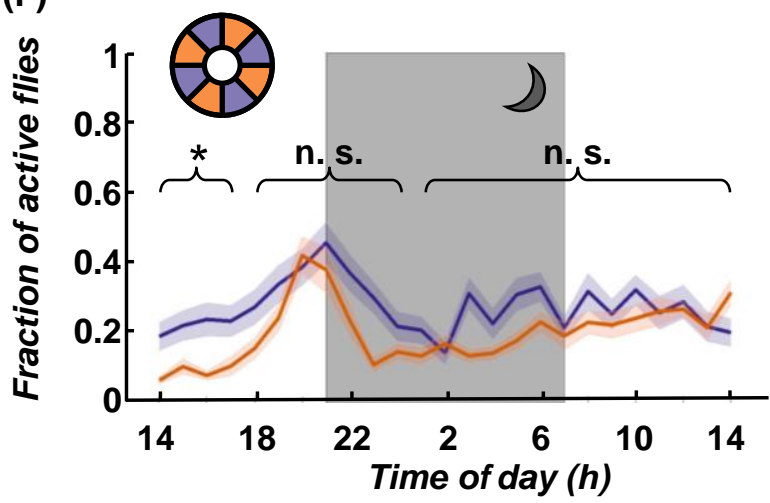

19:00 - 19:30

(H)

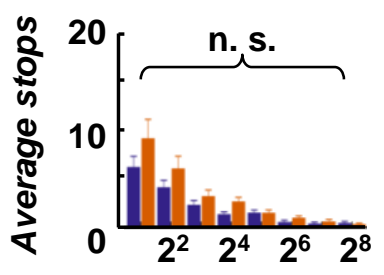

Duration (sec)
(I)

(C)
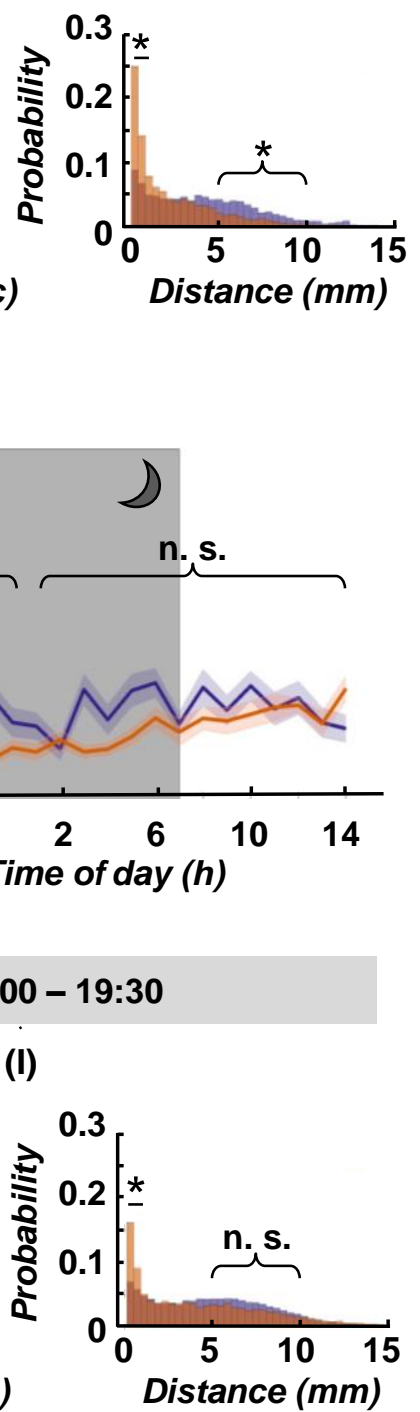

(D)

$31-60 \mathrm{~min}$
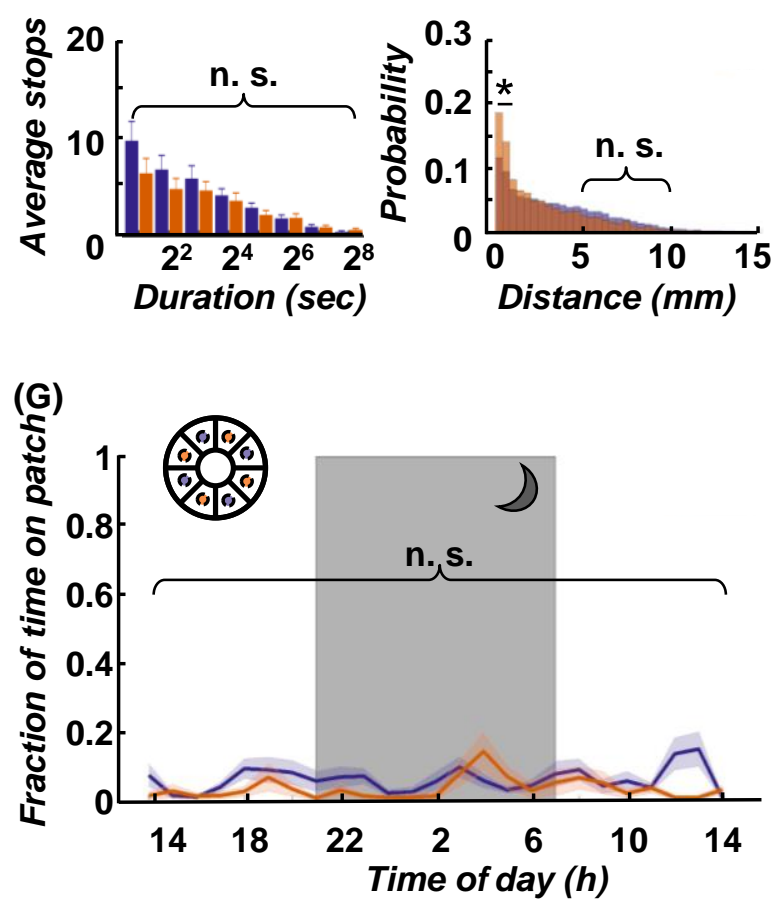

08:30 - 09:00

(J)

(K)
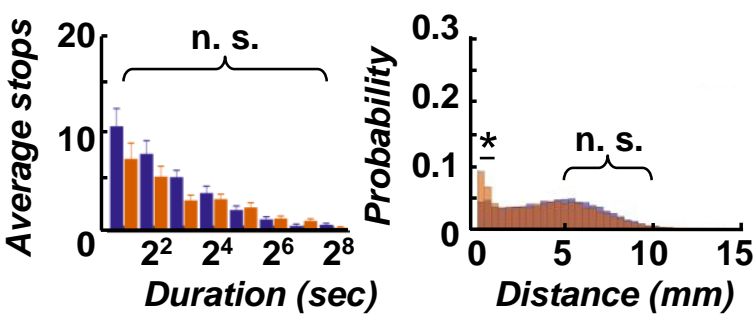

Figure 6 
(which was not certified by peer review) is the author/funder, who has granted bioRxiv a license to display the preprint in perpetuity. It is $\mathrm{m}$ available under aCC-BY-NC-ND 4.0 International license.

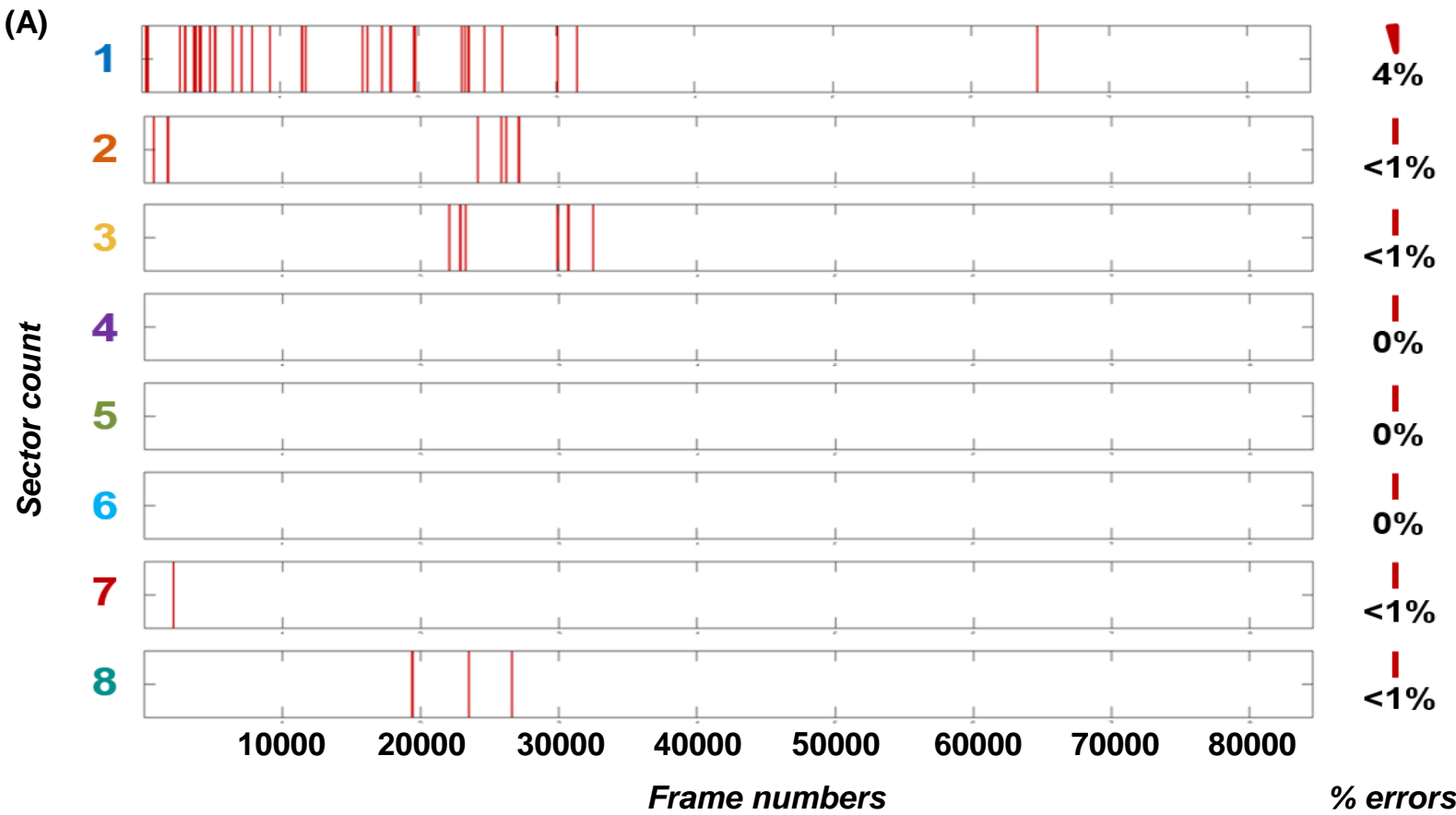

(B)

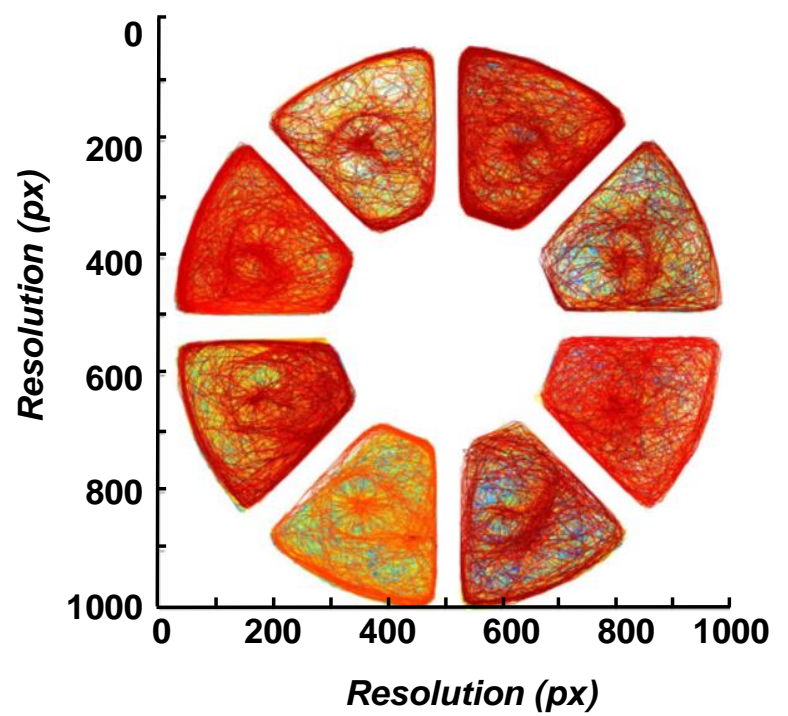

(D)

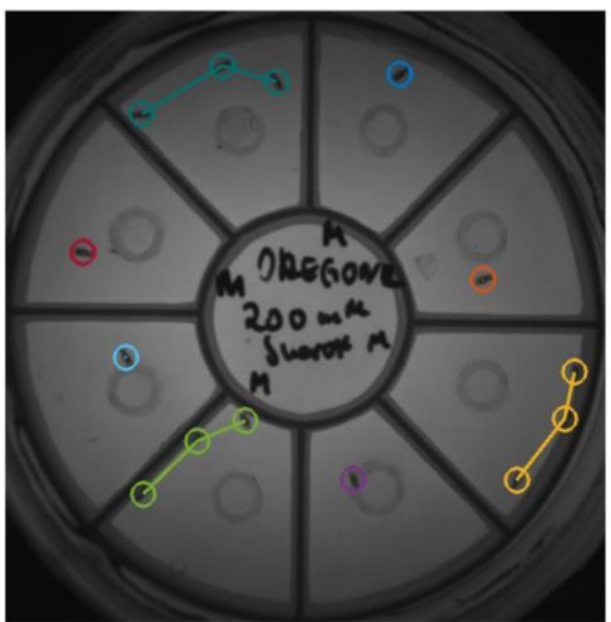

(C)

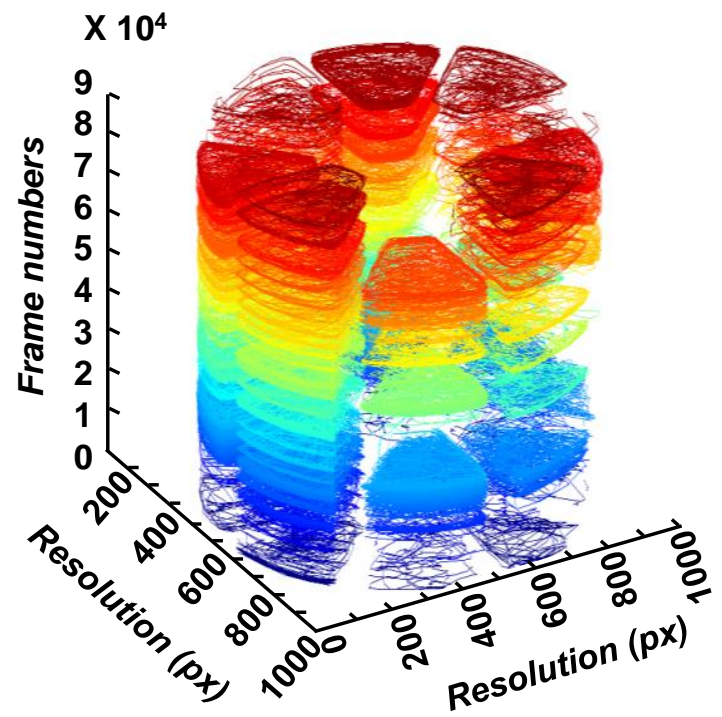

